\title{
Global Terrestrial Water Storage and Drought Severity under Climate Change
}

Yadu Pokhrel $^{1 *}$, Farshid Felfelani ${ }^{1}$, Yusuke Satoh ${ }^{2}$, Julien Boulange ${ }^{2}$, Peter Burek ${ }^{3}$, Anne Gädeke $^{4}$, Dieter Gerten ${ }^{4,5}$, Simon N. Gosling ${ }^{6}$, Manolis Grillakis ${ }^{7}$, Lukas Gudmundsson ${ }^{8}$, Naota Hanasaki ${ }^{2}$, Hyungjun $\mathrm{Kim}^{9}$, Aristeidis Koutroulis ${ }^{7}$, Junguo Liu ${ }^{10}$, Lamprini Papadimitriou ${ }^{11}$, Jacob Schewe ${ }^{4}$, Hannes Müller Schmied ${ }^{12,13}$, Tobias Stacke ${ }^{14}$, Camelia-Eliza Telteu ${ }^{12}$, Wim Thiery ${ }^{15,8}$, Ted Veldkamp ${ }^{16,17}$, Fang Zhao ${ }^{18,4}$ and Yoshihide Wada ${ }^{3,17}$

${ }^{1}$ Department of Civil and Environmental Engineering, Michigan State University, East Lansing, MI, USA

${ }^{2}$ National Institute for Environmental Studies, Tsukuba, Japan

${ }^{3}$ International Institute for Applied Systems Analysis, Laxenburg, Austria

${ }^{4}$ Potsdam Institute for Climate Impact Research (PIK), Member of the Leibniz Association, Potsdam, Germany

${ }^{5}$ Humboldt-Universität zu Berlin, Berlin, Germany

${ }^{6}$ School of Geography, University of Nottingham, Nottingham, UK

${ }^{7}$ School of Environmental Engineering, Technical University of Crete, Chania, Greece

${ }^{8}$ Institute for Atmospheric and Climate Science, ETH Zurich, Zurich, Switzerland

${ }^{9}$ Institute of Industrial Science, the University of Tokyo, Tokyo, Japan

${ }^{10}$ School of Environmental Science and Engineering, Southern University of Science and Technology, Shenzhen, China

${ }^{11}$ Cranfield Water Science Institute (CWSI), Cranfield University, Cranfield, Bedfordshire, UK

${ }^{12}$ Institute of Physical Geography, Goethe-University Frankfurt, Frankfurt am Main, Germany

${ }^{13}$ Senckenberg Leibniz Biodiversity and Climate Research Centre Frankfurt (SBiK-F), Frankfurt am Main, Germany

${ }^{14}$ Institute of Coastal Research, Helmholtz-Zentrum Geesthacht (HZG), Geesthacht, Germany

${ }^{15}$ Department of Hydrology and Hydraulic Engineering, Vrije Universiteit Brussel, Brussels, Belgium

${ }^{16}$ Department of Water \& Climate Risk, VU University, Amsterdam, the Netherlands

${ }^{17}$ Department of Physical Geography, Utrecht University, Utrecht, Netherlands

${ }^{18}$ School of Geographic Sciences, East China Normal University, Shanghai, China

*e-mail: ypokhrel@egr.msu.edu 
Terrestrial water storage (TWS) modulates the hydrological cycle and is a key determinant of water availability and an indicator of drought. While historical TWS variations have been increasingly studied, future changes in TWS and the linkages to droughts remain unexamined. Here, using ensemble hydrological simulations, we show that climate change could reduce TWS in many regions, especially those in the Southern Hemisphere. Strong inter-ensemble agreement indicates high confidence in the projected changes that are driven primarily by climate forcing, rather than land and water management activities. Declines in TWS translate to increases in future droughts. By the late-twenty-first century, global land area and population in extreme-to-exceptional TWS drought could more than double, each increasing from 3\% during 1976-2005 to $7 \%$ and $8 \%$, respectively. Our findings highlight the importance of climate change mitigation to avoid adverse TWS impacts and increased droughts, and the need for improved water resource management and adaptation.

TWS - the sum of continental water stored in canopies, snow and ice, rivers, lakes and reservoirs, wetlands, soil, and groundwater - is a critical component of the global water and energy budget. It plays key roles in determining water resource availability ${ }^{1}$ and modulating water flux interactions among various Earth system components ${ }^{2}$. Further, TWS changes are inherently linked to droughts ${ }^{2-6}$, floods ${ }^{7}$, and global sea level change ${ }^{8-11}$. Despite such importance, global TWS remains less studied relative to hydrological fluxes (for example, river discharge, evapotranspiration, and groundwater flow) owing to the lack of large-scale observations and challenges in explicitly resolving all TWS components in hydrological modelling ${ }^{12}$. This generally holds true for historical analyses; crucially, no study has to date examined the potential impacts of future climate change on global TWS.

Recent modelling advancements ${ }^{13}$ have improved the representation of TWS in global hydrological models $\mathrm{s}^{14,15}$ (GHMs) and land surface models ${ }^{12}$ (LSMs). The Gravity Recovery and Climate Experiment (GRACE) satellite mission provided added opportunities to improve and validate TWS simulations in these models. GRACE TWS data and model simulations, often in combination, have been used for wide-ranging applications including the assessment of water resources and impacts of human activities on the water cycle ${ }^{14,16}$, quantifying aquifer depletion $^{12,14,17-19}$, monitoring drought ${ }^{3-6,20}$, and assessing flood potential ${ }^{7}$. These studies have advanced the understanding of global TWS systems that are continually changing under natural hydroclimatic variability and accelerating human land and water management activities, but the focus has been on historical variabilities in TWS. Further, future projections from general circulation models (GCMs) have been used to quantify climate change impacts on hydrological fluxes $^{21-23}$ and storages, but the projections of storages are limited to a subset of TWS components - specifically soil moisture and snow ${ }^{24-26}$ - owing to an incomplete representation of TWS components in the GCMs. Lack of explicit parameterizations for surface water and groundwater processes and use of shallow rooting depth in GCMs have particularly hindered comprehensive TWS projections using GCM simulations ${ }^{25}$.

Because TWS represents total water availability on land, it also provides an integrated measure of overall drought condition in a region ${ }^{5,6}$. Drought - a slow-evolving phenomenon-is among the costliest natural disasters ${ }^{27}$, directly affecting water resources, agriculture, socioeconomic 
development, and ecosystem health and often linked with armed conflicts ${ }^{28}$. Substantial literature exists on the study of droughts using indices such as the standardized precipitation index $\left(\mathrm{SPI}^{29}\right)$, Palmer drought severity index $\left(\mathrm{PDSI}^{30}\right)$, soil moisture drought index $\left(\mathrm{SMI}^{31,32}\right)$, and standardized runoff index $\left(\mathrm{SRI}^{33}\right)$. These conventional indices have been used in monitoring and projecting ${ }^{32,34}$ meteorological, agricultural, and hydrological droughts ${ }^{35}$. Recently, a new drought index, the TWS drought severity index (TWS-DSI ${ }^{5}$ ), has been employed to examine droughts ${ }^{36,37}$ in relation to the vertically-integrated water storage as opposed to the individual storages or fluxes used in conventional indices. Previous studies ${ }^{5,36,37}$ have demonstrated that TWS-DSI correlates with the conventional indices in regions with long-term water storage change but provides an integrated measure, especially by capturing the effects of slow-responding terms (such as deep soil moisture and groundwater). Further, an increasing number of TWS-based drought studies have shown that combining TWS with traditional drought indices can provide crucial insights about drought impacts on hydrologic systems and vegetation growth ${ }^{6,36,37}$, because TWS directly responds to changes in precipitation, integrates soil moisture, and modulates runoff generation, hence encompassing the three aforementioned drought types ${ }^{36}$. However, since previous TWS studies have focused on historical droughts ${ }^{3-6,20}$, the changes in future droughts due to TWS change and variability remain unexamined.

Here we present a global assessment of the impacts of future climate change on TWS. We then examine the changes in drought severity and frequency resulting from climate-induced TWS change and variability by using the monthly TWS-DSI ${ }^{5}$ (see Methods and Supplementary Table 1). We use multi-model hydrological simulations (27 ensemble members; Supplementary Table 2) from seven terrestrial hydrology models (LSMs and GHMs; Supplementary Table 3) driven by atmospheric forcing from four GCMs (see Methods). Four cases of radiative forcing are considered for each GCM: the pre-industrial control (PIC), historical climate (HIST), and low (Representative Concentration Pathway; RCP2.6) and medium-high (RCP6.0) emission scenarios (see Methods). Simulations are conducted under the framework of the Inter-Sectoral Impact Model Intercomparison Project, phase 2b (ISIMIP2 $b^{38}$; https://www.isimip.org/). We use the multi-model weighted mean of TWS anomalies, calculated by weighting the ensemble members based on their continent-level skill and independence scores ${ }^{39}$ (Methods; Extended Data Figs. 1 and 2).

\section{TWS under climate change}

By the mid- (2030-2059) and late- (2070-2099) twenty-first century, TWS is projected to substantially decline in the majority of the Southern Hemisphere, the conterminous U.S., most of Europe and the Mediterranean, but increase in eastern Africa, south Asia and northern high latitudes, especially northern Asia (Fig. 1). The latitudinal mean (Fig. 1) indicates a larger decline in TWS in the Southern Hemisphere than in the North, driven primarily by the decline in South America and Australia; this is in line with the projected precipitation changes (Extended Data Fig. 3) and could partly be due to a tendency of GCMs to overestimate ${ }^{27}$ drying trends in the Southern Hemisphere. The changes are evident by the mid-twenty-first century (under both RCPs; Figs. 1a and c), but the signal becomes stronger by the late-twenty-first century, especially under RCP6.0 (Fig. 1d). Exceptions are found in parts of the conterminous U.S., where TWS under RCP2.6 is projected to decline by mid-century but then increase slightly thereafter, due to the projected increase in precipitation across most of the region (Extended Data Fig. 3) combined with a decrease in temperature from the mid- to the late-twenty-first century 
(Extended Data Fig. 4). For RCP6.0, the projected changes (positive or negative) seen during mid-century become more pronounced later for most global regions. The differences between the two RCPs are, however, less obvious for both periods; an exception is Australia where the spatial extent of decline in TWS is projected to be smaller under RCP6.0 than under RCP2.6 (Fig. 1), which aligns with wetter conditions projected in RCP6.0 (Extended Data Fig. 3). Globally, TWS declines (increases) in 67\% (33\%) of land area (excluding Greenland, Antarctica, and glaciers) by the late-twenty-first century under RCP6.0.

Overall, strong agreement is found across ensemble members in the sign of change (color century, an agreement of $>50 \%$ can be seen in regions where a large decline or increase in TWS is projected; such agreement is $>75 \%$ for regions such as the Amazon basin, southern Australia, the Mediterranean, and eastern U.S. (Fig. 1). This confidence is reinforced by the good agreement between the simulated TWS and GRACE data for the historical period (Extended Data Fig. 5 and Supplementary Figs. 1-2). The broad global spatial patterns and seasonal variations in TWS are accurately captured by the multi-model ensemble mean, although some differences are evident in the magnitude of seasonal amplitude (Extended Data Fig. 5). Such differences stand out especially along major river channels (such as the Amazon, Nile, and Mississippi) that are explicitly considered in the models but not resolved in the GRACE data. Further, the seasonal dynamics and interannual variability in the simulated TWS averaged over the major global river basins also agree reasonably well with the GRACE data (Supplementary Figs. 1-2), even though there are some disagreements between the trend in GRACE and multimodel mean (Supplementary Fig. 2), likely due to uncertainties in model parameterizations and potential biases in GCM-based forcing data.

\section{Uncertainty in TWS simulations}

The inter-ensemble spread in TWS simulations is a combination of the uncertainties arising from climate forcing (driven by GCMs) and GHM/LSM parameterizations (see Methods). The GCM uncertainty (for a given RCP scenario) is larger than GHM/LSM uncertainty in most regions for the historical period and mid-twenty-first century (Fig. 2). However, the GHM/LSM uncertainty increases substantially with time, leading to a higher GHM/LSM uncertainty in most regions by the late-twenty-first century, especially under RCP6.0. The GHM/LSM uncertainty range (Fig. 2, two right panels) for the historical period is relatively small, consistent with good agreement of the seasonal amplitude and temporal variability of TWS with GRACE data (Extended Data Fig. 5 and Supplementary Figs. 1-2), which likely reflects the relative benefits of bias correction using observations for the same period.

\section{Regional variability and seasonality in TWS projections}

The projected changes in the seasonal cycle of TWS also vary regionally (Fig. 3; Supplementary Fig. 3). The Amazon, South Europe/Mediterranean (MED), North Australia (NAU), North-East Brazil, South Australia/New Zealand (SAU), Southeastern South America (SSA), and West Africa (WAF) are projected to experience a decline in TWS across all seasons. In Alaska, a slight increase is observed during winter months - likely due to an increase in snow amountbut a discernible decline is seen during summer-to-fall months, potentially caused by a warmingdriven increase in evapotranspiration. In regions where TWS is expected to increase, changes in the seasonal cycle vary. While South Asia (SAS) could experience an increase in TWS across all 
seasons, increases are projected only during late fall to early spring in North Asia (NAS); in East Africa (EAF), increases are expected in all seasons but only under RCP6.0. Many of the regions projected to experience an increase in TWS overlap with regions with higher future precipitation (Extended Data Fig. 3). We find the strong drying in MED to be consistent with the historicallyobserved north (wet)-south (dry) contrast in pan-European river flows ${ }^{40}$, implying that the regions with historical drying trends are expected to become even drier under climate change. Our results for the Amazon also corroborate the widely-discussed drying and lengthening of the dry season ${ }^{41}$, suggesting that the findings are robust for this region and add to the longstanding debate on the fate of the Amazonian rainforest under a warmer, drier future ${ }^{42}$.

Soil moisture has been used previously as an indicator of total TWS, on the basis that its variability constitutes a large portion of the total TWS variability ${ }^{26}$. We find that the component contribution ratio (CCR; Methods) of soil moisture to total TWS varies substantially among SREX regions. Generally, soil moisture contribution is high (>50\%) in relatively dry regions, including Central America/Mexico (CAM), MED, West Asia (WAS), Central Asia (CAS), WAF, Southern Africa (SAF), and SAU, and low in relatively humid and snow-dominated regions including Alaska, NAS, and Amazon (Extended Data Fig. 6), as also noted by previous studies ${ }^{16,43}$. The results suggest that soil moisture could not be used to substitute TWS globally.

Changes in TWS are driven primarily by climate forcing, as opposed to land and water management and/or socioeconomic drivers (see Methods). This is apparent from comparing the HIST and RCP simulations with the PIC simulations (see Methods) for the baseline period and late-twenty-first century (Fig. 3). Since the PIC simulations use identical socio-economic scenarios as the HIST and RCP simulations for the respective periods (Supplementary Table 2), the PIC (2070-2099) versus PIC (1976-2005) comparison suggests that TWS would have remained generally stable in most regions under a pre-industrial climate. Differences between the two simulations can, however, be seen in some regions (e.g., EAF, SSA, WAS) even though the difference in the global average is relatively small (Fig. 3). Globally, this difference is $\sim 11 \%$ of the difference between RCP6.0 (2070-2099) and PIC (1976-2005), meaning that $\sim 90 \%$ of the projected change could be attributed to climate change. A decrease in TWS is projected under pre-industrial climate in CAM, EAF, and NAU. Other regions including Central North America (CAN), Amazon, SSA, WAS, and SAU would have been wetter in the future under pre-industrial climate. These results suggest that while the wetting caused by climate change could be offset by human land and water management and socio-economic drivers in some regions (such as EAF), the climate-induced drying could be further exacerbated by human activities in others (including NAU).

\section{Future projection of TWS drought}

The projected changes in TWS correspond with shifts in future drought occurrence and severity. Many regions are projected to experience an increased occurrence of moderate-to-severe $(-0.8 \leq$ TWS-DSI $<-1.6)$ and extreme-to-exceptional (TWS-DSI $\leq-1.6$; see Methods and Supplementary Table 1) droughts (Figs. 4a and b). The direction of change is robust among ensemble members, especially in regions that are projected to experience an increase in the number of drought days (for example Amazon, Mediterranean, conterminous U.S., Southeast Asia, and parts of Australia). By the late-twenty-first century (RCP6.0), the frequency of moderate, severe, extreme, and exceptional droughts is projected to increase substantially (17- 
34\%; Supplementary Table 4) in all continents but Asia (Figs. 4c and 4e-h). This is caused largely by a significant reduction in the frequency of near-normal to abnormally dry and slightly near-normal and wet conditions in South America and Australia. Further, results suggest a general reduction in the frequency of wet conditions globally except in Asia and, to some extent, in Africa. Asia stands out among all continents where the frequency of severe, extreme, and exceptional droughts as well as that of moderately wet to exceptionally wet conditions is projected to increase, caused by a reduced frequency of near-normal and slightly dry and wet conditions (Fig. 4d).

Global land area and projected future population (see Methods) exposed to moderate-to-severe drought are projected to increase steadily until the mid-twenty-first century and remain relatively stable during the late-twenty-first century. However, those under extreme-to-exceptional drought are projected to increase until the end of the century (Figs. 4i-j) with a noticeable increase in inter-ensemble spread toward the late-century, consistent with the increase in GHM/LSM uncertainty (Fig. 2). Under RCP6.0, both global land area and projected population in moderateto-severe drought increase from 15\% during the baseline period of 1976-2005 to $18 \%$ and 20\%, respectively, by the mid- and late-twenty-first century. This change in population translates to an additional $\sim 600$ and $\sim 859$ million people, respectively. From the mid- to the late-twenty-first century, the global population in moderate-to-severe drought for at least 30 days per year increases from $59 \%$ to $63 \%$, and population experiencing at least 60 days per year increases from $45 \%$ to $49 \%$. For extreme-to-exceptional drought under RCP6.0, land area increases from a 3\% baseline to $4 \%$ and $7 \%$ during the mid- and late-twenty-first century, respectively. Population exposed to these conditions increases from a baseline of $3 \%$ to $4 \%$ and $8 \%$, or an additional $\sim 154$ and 488 million people. The population exposed to at least 30 days of extreme-to-exceptional drought increases from $19 \%$ to $27 \%$, and at least 60 days from $11 \%$ to $18 \%$, between the midand late-twenty-first-century.

At the regional scale, the frequency of extreme and exceptional droughts is projected to increase by the late-twenty-first century in most SREX regions (Fig. 5; Methods). The changes in drought frequency are evident under both RCPs but are generally more pronounced under RCP 6.0. Overall, the probability density functions (PDFs) characterized by a symmetrical distribution (centered at TWS-DSI=0) for the historical period tend to become more positively skewed in most regions where TWS is expected to decline (see Figs. 1 and 3), meaning that these regions are likely to experience more frequent and intense droughts in the future. For example, in the Amazon the occurrence of severe, extreme, and exceptional droughts (Supplementary Table 1) increases substantially (under both RCPs) by mid- and late-twenty-first century (Fig. 5). The dryseason TWS deficit in the Amazon is suggested to be increasing, causing more frequent and intense droughts ${ }^{20,44}$, and our findings highlight that the drying would further intensify, with important implications for the resilience of the Amazon rainforest.

Distributions with obvious positive skew for the future periods can be observed in CAM, CNA, MED, NAU, SAU, WAF and WAS. Conversely, regions such as EAF, NAS and SAS are projected to experience a reduced frequency of TWS droughts. For West North America and the entire globe, a shift in the PDFs to a bimodal distribution can be seen, suggesting an increased frequency of both TWS droughts and anomalously wet conditions, further indicating a reduced 
TWS buffer capacity under future climate. Finally, results indicate that in the absence of greenhouse gas forcing (PIC simulation; Fig. 5), future droughts would have either not changed noticeably or their severity could have been reduced in many regions, suggesting that the exacerbations in drought conditions are attributable primarily to climate change.

A comparison of TWS-DSI with traditional drought indices (Methods; Extended Data Figs. 710) suggests that TWS-DSI provides new information on future droughts. Unlike SRI that is highly correlated with SPI, TWS-DSI exhibits different PDFs in most SREX regions (Fig. 5 and Extended Data Figs. 7-8) because it encompasses all relevant storage components related to drought and accounts for human land and water management that directly alters water availability. We find TWS-DSI also differs from soil moisture-based indices (Fig. 5 and Extended Data Figs. 9-10) because the soil moisture contribution to total TWS varies significantly among regions (Extended Data Fig. 6); TWS-DSI captures the effects of groundwater and surface water storages and accounts for human land and water management activities not reflected in the other indices. These comparisons - supported by previous studies on historical droughts ${ }^{6,36,37}$-indicate that TWS-DSI could be used synergistically with traditional drought indices to better understand and predict droughts by accounting for the role of groundwater and human activities.

\section{Summary and implications}

These results show that climate change could reduce TWS in many regions, especially in the Southern Hemisphere, the U.S. and southwestern Europe; exceptions are regions with high increases in precipitation, including east Africa and northern Asia. By the late-twenty-first century and under RCP6.0, two-thirds of the global land could experience a reduction in TWS. We find strong agreement among ensemble model projections, especially in the direction of change, suggesting that the results are robust. We further show that extreme droughts are expected to become more frequent in most of the SREX regions. Globally, land area and projected population in extreme-to-exceptional TWS drought under RCP6.0 are projected to more than double, each increasing from 3\% to $7 \%$ and $8 \%$, respectively, by the late-twenty-first century.

While we use state-of-the-art models and the best available global data available, there are limitations to our approach. First, even though the GHMs/LSMs reproduce historical TWS variability well, these models and the GCM forcing data contain inherent biases ${ }^{9}$. Second, assessment of the relative contributions of individual TWS components is limited to soil moisture, because the other components are not currently available from ISIMIP2b simulations. Lastly, the implications of vegetation response to rising $\mathrm{CO}_{2}$ levels on TWS and drought projections are not considered, because the hydrological models (except LPJmL) do not currently simulate vegetation dynamics. Studies have shown that elevated atmospheric $\mathrm{CO}_{2}$ levels lead to increased leaf-level water use efficiency, potentially ameliorating the reduction in water availability through reduced evapotranspiration and increased soil moisture and runoff ${ }^{45,46}$. This implies that the projected decline in TWS and increase in future droughts may be overestimated in our study. However, increased foliage area under elevated $\mathrm{CO}_{2}$ levels and warmer climate generally lead to increased vegetation growth and associated water use, resulting in decreased water availability by counterbalancing the increase in runoff from water-use efficiency gains ${ }^{47,48}$. Thus a comprehensive analysis of TWS projections using coupled hydrological-dynamic 
vegetation models is required for a robust estimation of the implications of vegetation response to elevated $\mathrm{CO}_{2}$ levels, which should be a priority for future studies.

Despite some limitations, our study provides a comprehensive assessment of climate impacts on future TWS and droughts. Given large uncertainties and medium confidence in drought projections using traditional drought indices ${ }^{49}$, and since no single drought index can capture the

\section{References}

3231 Rodell, M. et al. Emerging trends in global freshwater availability. Nature 557, 651 (2018).

3242 Tapley, B. D. et al. Contributions of GRACE to understanding climate change. Nature Climate Change, 1 (2019).

3 Thomas, A. C., Reager, J. T., Famiglietti, J. S. \& Rodell, M. A GRACE - based water storage deficit approach for hydrological drought characterization. Geophysical Research Letters $\mathbf{4 1}$, 1537-1545 (2014).

$4 \quad$ Houborg, R., Rodell, M., Li, B., Reichle, R. \& Zaitchik, B. F. Drought indicators based on model - assimilated Gravity Recovery and Climate Experiment (GRACE) terrestrial water storage observations. Water Resources Research 48 (2012).

5 Zhao, M., Velicogna, I. \& Kimball, J. S. Satellite observations of regional drought severity in the continental United States using GRACE-based terrestrial water storage changes. J. Climate 30, 6297-6308 (2017).

6 Long, D. et al. GRACE satellite monitoring of large depletion in water storage in response to the 2011 drought in Texas. Geophysical Research Letters 40, 3395-3401 (2013).

7 Reager, J., Thomas, B. \& Famiglietti, J. River basin flood potential inferred using GRACE gravity observations at several months lead time. Nature Geoscience 7, 588 (2014).

8 Pokhrel, Y. et al. Model estimates of sea-level change due to anthropogenic impacts on terrestrial water storage. Nature Geoscience 5, 389-392, doi:10.1038/ngeo1476 (2012).

9 Scanlon, B. R. et al. Global models underestimate large decadal declining and rising water storage trends relative to GRACE satellite data. PNAS, 201704665 (2018).

10 Reager, J. et al. A decade of sea level rise slowed by climate-driven hydrology. Science 351, 699703 (2016).

11 Wang, J. et al. Recent global decline in endorheic basin water storages. Nature geoscience 11, 926 (2018).

12 Pokhrel, Y. et al. Incorporation of groundwater pumping in a global Land Surface Model with the representation of human impacts. Water Resources Research 51, 78-96, doi:10.1002/2014WR015602 (2015).

13 Wada, Y. et al. Human-water interface in hydrological modelling: current status and future directions. Hydrol. Earth Syst. Sci. 21, 4169-4193, doi:10.5194/hess-21-4169-2017 (2017).

14 Döll, P., Müller Schmied, H., Schuh, C., Portmann, F. T. \& Eicker, A. Global-scale assessment of groundwater depletion and related groundwater abstractions: Combining hydrological modeling with information from well observations and GRACE satellites. Water Resources Research 50, 5698-5720, doi:10.1002/2014WR015595 (2014).

15 Hanasaki, N., Yoshikawa, S., Pokhrel, Y. \& Kanae, S. A global hydrological simulation to specify the sources of water used by humans. Hydrol. Earth Syst. Sci. 22, 789-817, doi:10.5194/hess-22-789-2018 (2018). 
Felfelani, F., Wada, Y., Longuevergne, L. \& Pokhrel, Y. Natural and human-induced terrestrial water storage change: A global ant in India. Nature 460, 999-1002, doi:10.1038/nature08238 (2009). Scanlon, B. R. et al. Groundwater depletion and sustainability of irrigation in the US High Plains and Central Valley. PNAS 109, 9320-9325, doi:10.1073/pnas.1200311109 (2012).

19 Famiglietti, J. S. et al. Satellites measure recent rates of groundwater depletion in California's Central Valley. Geophysical Research Letters 38, L03403, doi:10.1029/2010GL046442 (2011).

20 Chaudhari, S., Pokhrel, Y., Moran, E. \& Miguez-Macho, G. Multi-decadal hydrologic change and variability in the Amazon River basin: understanding terrestrial water storage variations and drought characteristics. Hydrol. Earth Syst. Sci. 23, 2841-2862, doi:10.5194/hess-23-2841-2019 (2019).

21 Schewe, J. et al. Multimodel assessment of water scarcity under climate change. PNAS 111, 3245-3250, doi:10.1073/pnas.1222460110 (2014).

22 Oki, T. \& Kanae, S. Global Hydrological Cycles and World Water Resources. Science 313, 10681072, doi:10.1126/science.1128845 (2006).

23 Ferguson, C., Pan, M. \& Oki, T. The effect of global warming on future water availability: CMIP5 synthesis. Water Resources Research 54, 7791-7819 (2018).

24 Pokhrel, Y., Fan, Y. \& Miguez-Macho, G. Potential hydrologic changes in the Amazon by the end of the twenty-first century and the groundwater buffer. Environmental Research Letters $\mathbf{9}$, doi:10.1088/1748-9326/9/8/084004 (2014).

25 Jensen, L., Eicker, A., Dobslaw, H., Stacke, T. \& Humphrey, V. Long - term wetting and drying trends in land water storage derived from GRACE and CMIP5 models. J. Geophys. Res. Atmos. (2019).

26 Freedman, F. R., Pitts, K. L. \& Bridger, A. F. Evaluation of CMIP climate model hydrological output for the Mississippi River Basin using GRACE satellite observations. Journal of Hydrology 519, 3566-3577 (2014).

27 Nasrollahi, N. et al. How well do CMIP5 climate simulations replicate historical trends and patterns of meteorological droughts? Water Resources Research 51, 2847-2864 (2015). Mach, K. J. et al. Climate as a risk factor for armed conflict. Nature, 1 (2019).

29 McKee, T. B., Doesken, N. J. \& Kleist, J. in Proceedings of the 8th Conference on Applied Climatology. 179-183 (Boston).

30 Palmer, W. Meteorological Drought. US Weather Bureau, Washington, DC Research Paper No. 45, 58 (1965).

31 Samaniego, L., Kumar, R. \& Zink, M. Implications of parameter uncertainty on soil moisture drought analysis in Germany. Journal of Hydrometeorology 14, 47-68 (2013).

32 Sheffield, J. \& Wood, E. F. Projected changes in drought occurrence under future global warming from multi-model, multi-scenario, IPCC AR4 simulations. Climate Dynamics 31, 79-105, doi:10.1007/s00382-007-0340-z (2008).

33 Shukla, S. \& Wood, A. W. Use of a standardized runoff index for characterizing hydrologic drought. Geophysical research letters 35 (2008).

34 Dai, A. Increasing drought under global warming in observations and models. Nature climate change 3, 52-58 (2013).

35 Van Loon, A. F. Hydrological drought explained. WIREs Water 2, 359-392 (2015).

36 Du, J. et al. Multicomponent Satellite Assessment of Drought Severity in the Contiguous United States From 2002 to 2017 Using AMSR - E and AMSR2. Water Resources Research 55, 5394$406 \quad 5412(2019)$. 
Geruo, A. et al. Satellite-observed changes in vegetation sensitivities to surface soil moisture and total water storage variations since the 2011 Texas drought. Environmental Research Letters 12, 054006 (2017). Inter-Sectoral Impact Model Intercomparison Project (ISIMIP2b). Geosci. Model Dev. 10, 43214345, doi:10.5194/gmd-10-4321-2017 (2017).

39 Sanderson, B. M., Wehner, M. \& Knutti, R. Skill and independence weighting for multi-model assessments. Geosci. Model Dev. 10, 2379-2395, doi:10.5194/gmd-10-2379-2017 (2017).

40 Gudmundsson, L., Seneviratne, S. I. \& Zhang, X. Anthropogenic climate change detected in European renewable freshwater resources. Nature Climate Change 7, 813 (2017). Boisier, J. P., Ciais, P., Ducharne, A. \& Guimberteau, M. Projected strengthening of Amazonian dry season by constrained climate model simulations. Nature Climate Change 5, 656-660 (2015). physiology on the continental hydrologic cycle in response to increasing CO2. PNAS 115, 40934098 (2018).

47 Mankin, J. S., Seager, R., Smerdon, J. E., Cook, B. I. \& Williams, A. P. Mid-latitude freshwater availability reduced by projected vegetation responses to climate change. Nature Geoscience 12, 983-988 (2019).

48 Singh, A., Kumar, S., Akula, S., Lawrence, D. M. \& Lombardozzi, D. L. Plant growth nullifies the effect of increased water - use efficiency on streamflow under elevated $\mathrm{CO} 2$ in the Southeastern United States. Geophysical Research Letters 47, e2019GL086940 (2020).

49 Seneviratne, S. I. et al. in Managing the Risks of Extreme Events and Disasters to Advance Climate Change Adaptation (ed C. B. Field) 109-230 (Cambridge University Press, 2017).

50 Wanders, N., Loon, A. F. V. \& Van Lanen, H. A. Frequently used drought indices reflect different drought conditions on global scale. Hydrology and Earth System Sciences Discussions, $1-16$ (2017). 


\section{Methods}

444 Models, simulation settings, and forcing data. The seven terrestrial hydrology models used in this study include five global hydrological models $\left(\mathrm{GHMs}^{51}\right): \mathrm{CWatM}^{52}, \mathrm{H}_{0} 8^{15,53,54}, \mathrm{MPI}-\mathrm{HM}^{55}$, PCR-GLOBWB ${ }^{56}$, and WaterGAP2 ${ }^{57}$; one global land surface model (LSM ${ }^{51}$ ): CLM4. $5^{58}$; and one dynamic global vegetation model (DGVM): LPJmL ${ }^{59}$. All models simulate the key terrestrial hydrological (e.g., soil, vegetation, river) processes (Supplementary Table 3). Meteorological forcing data are derived from climate simulations by four of the GCMs (a subset of models participating in the Coupled Model Intercomparison Project Phase 5; CMIP5) included in the Fifth Assessment Report (AR5) of the Intergovernmental Panel on Climate Change (IPCC): GFDL-ESM2M, HadGEM2-ES, IPSL-CM5A-LR, and MIROC5. The climate variables included in the forcing data are precipitation, air temperature, solar radiation (short and long wave), wind speed, specific humidity, and surface pressure, which are bias adjusted ${ }^{60}$ and downscaled to $0.5^{\circ} \times 0.5^{\circ}$ spatial resolution of the terrestrial hydrology models. A comprehensive description of bias adjustment and downscaling can be found in the previous literature ${ }^{60-62}$.

For each GCM, four radiative forcing cases are considered for varying periods (Supplementary Table 2): the pre-industrial control (PIC; pre-industrial climate; 1861-2099), historical climate (HIST; that includes the effects of human emissions including greenhouse gases and aerosols ${ }^{63}$; 1861-2005), low greenhouse gas concentration scenario (RCP2.6; 2006-2099), and medium-high greenhouse gas concentration scenario (RCP6.0; 2006-2099). Simulations are conducted under the standard protocol of the Group- 2 simulation scenario design of the Inter-Sectoral Impact Model Intercomparison Project phase 2b (ISIMIP2 $b^{38}$; https://www.isimip.org/). The two RCPs are the only RCPs for which TWS results from all models were available from ISIMIP2b simulations. The hydrology models are run for each GCM-radiative forcing combination by considering time-varying human land and water management activities and socio-economic conditions for the HIST runs but fixed at the present day (i.e., 2005) level for future projections (2006-2099; RCP2.6 and RCP6.0). For the PIC simulations, climate forcing is set at the preindustrial level and human land and water management activities and socio-economic conditions vary for the historical period but are fixed at 2005 level for the future periods (see Fig. 1 in Frieler et al. ${ }^{38}$ ). Thus, while the difference between PIC and other radiative forcing cases results from pure climate change, the difference between historical and future PIC runs reflects the timevarying effects of human activities and socio-economic drivers, not climate change. The human activities and socio-economic indicators considered are population, national gross domestic product, land use and land cover change (LULCC), irrigated areas, fertilizer use, and reservoir operation including water withdrawal, depending on the model schemes. LULCC and irrigated areas are prescribed based on the HYDE3-MIRCA data ${ }^{64-66}$ and data for dams and reservoirs are taken from the GRanD database ${ }^{67}$. Irrigation (and other water use sector) schemes vary among models (Supplementary Table 3) but all models simulate global irrigation requirements within plausible limits of reported datasets based on country statistics (see reference to each model for more details). The reservoir operation schemes are based on Hanasaki et al. ${ }^{68}$ (H08 and WaterGAP2), Biemans et al. ${ }^{69}$ (LPJmL), and a combination of Haddeland et al. ${ }^{70}$ and Adams et al. $^{71}$ (CWatM and PCR-GLOBWB); reservoirs are not represented in MPI-HM and CLM4.5. Soil column depth and layer configuration and groundwater representation vary among models (Supplementary Table 3). 
Multi-model weighted mean. Multi-model mean is calculated by weighting the ensemble members based on their skill (i.e., the root mean squared error (RMSE) of the area-weighted seasonal cycle of TWS relative to GRACE data) and independence (i.e., a measure of how different model results are) scores, following previous studies ${ }^{39,72}$. The continent-based, temporally static weights $\left(w_{o}(i)\right)$ for the 27 ensemble members (Extended Data Fig. 1) are calculated as the normalized product of the skill and independence weights so that their sum is unity $^{39,72}$, i.e., $\left(\sum_{i=1}^{27} w_{o}(i)=1\right)$. The independence weight of member $i, w_{u}(i)$, is computed as the inverse of the summation of pairwise similarity score, $S\left(\delta_{i, j}\right)$, which ranges between 1 (for identical members) and 0 (for the most distinct members). Mathematically, $w_{u}(i)=\frac{1}{1+\sum_{j \neq i}^{27} S\left(\delta_{i, j}\right)}$. The pairwise similarity score is calculated as a function of the Euclidean distance ${ }^{39}$ between the members $\left(\delta_{i, j}\right)$, represented by the RMSE of the continentlevel average TWS seasonal cycle from two members, and a parameter called the radius of similarity $\left(D_{u}\right): S\left(\delta_{i, j}\right)=\exp \left(-\left(\frac{\delta_{i, j}}{D_{u}}\right)^{2}\right)$, where $\delta_{i, j}$ is normalized by the mean of pairwise intermodel distances (Extended Data Fig. 2). The parameter $D_{u}$ is the distance below which models are marked as similar and is resolved for each continent as a fraction of the distance between the best performing member (i.e., the model with the smallest RMSE) and GRACE through an iterative process ${ }^{39}$. The skill weighting of member $i, w_{q}(i)$, is calculated based on the stretched exponential function ${ }^{73}$ of the distance from GRACE ( $\delta_{i, G R A C E}$; the normalized RMSE of member $i$ 's TWS seasonal cycle against GRACE for 2002-2016) and the radius of model quality $\left(D_{q}\right): w_{q}(i)=\exp \left(-\left(\frac{\delta_{i, G R A C E}}{D_{q}}\right)^{2}\right)$, where smaller distances from the GRACE seasonal cycle result in larger skill score/weight. The parameter $D_{q}$ is also defined as a fraction of the distance between the best performing member and GRACE. This parameter controls the strength of the skill weighting. That is, when $D_{q}$ approaches zero, most of the simulations get significantly down-weighted and only the best performing model is assigned a high skill score. Conversely, as $D_{q}$ approaches infinity, all ensemble members are allotted a high (i.e., close to 1) skill score alike and therefore, the multi-model weighted mean approaches the non-skilled weighted mean. Finally, the continent-based $D_{q}$ values are estimated for 2002-2016 period and tested for RCP6.0 late-century simulations following a perfect model test and through an iterative procedure ${ }^{39}$. The perfect model test is conducted to ensure that out of sample simulations (i.e., simulations out of the GRACE period) are also improved with the weighting scheme. Note that the model weights are estimated by using the seasonal cycle of TWS, rather than the trend or inter-annual variability, because the original study ${ }^{39}$ that described the weighing scheme used the seasonality of climate variables, and no studies have demonstrated the applicability or robustness of the 
schemes based on trend or inter-annual variability. Further, the GRACE data period is relatively short to rely on temporal trends, which are highly sensitive to the time window chosen.

\section{Simulated TWS, GRACE data, model evaluation, and TWS variability under climate} change. The monthly-scale simulated TWS is derived by vertically integrating the surface and subsurface water storages, which include snow, canopy, river, reservoir (if simulated), lake (if simulated), wetland (if simulated), soil, and groundwater storages ${ }^{74,75}$. TWS derived from GRACE satellite measurements is used to evaluate the simulated TWS for the 2002-2016 period. We use the mean of mascon products ${ }^{76}$ from two processing centers: Center for Space Research (CSR) at the University of Texas at Austin, and Jet Propulsion Laboratory (JPL) at the California Institute of Technology. For model results, since the evaluation period is not covered completely by HIST simulations, we combine the results from HIST simulations (2002-2005) with results from RCP 2.6 (2006-2016). The seasonal mean of TWS anomalies (Extended Data Fig. 5 and Supplementary Fig. 1) is derived by first calculating the climatological mean seasonal cycle of TWS for the evaluation period and then taking the mean for each season. For consistency, the same reference period (2002-2016) is used in calculating the seasonal anomalies for both GRACE data and model simulations. Changes in TWS for the mid (2030-2059) and late (20702099) twenty-first century (for the two RCPs) are calculated by taking the difference of mean TWS for those periods to the mean TWS for the historical baseline period of 1976-2005, which is the last 30-year period of the historical simulations; simulations from year 2006 are conducted under future climate scenarios.

\section{Quantification of uncertainty in TWS simulations. The contribution of uncertainties from} GCMs (i.e., forcing data) and GHMs/LSMs to TWS is quantified by using the sequential sampling approach ${ }^{77}$. In this approach, the uncertainty contribution of GCMs and GHMs/LSMs is calculated using the range statistic ${ }^{77}$ of monthly TWS (represented as the quantile-based TWS index) averaged over the SREX regions for the historical baseline period, and mid- and latetwenty-first century. The GCMs (GHMs/LSMs) uncertainty - characterized as the range of mean in the quantile-based TWS index - for a given RCP scenario is computed by first averaging the quantile-based TWS index across all GHMs/LSMs (GCM) for each of the GCMs (GHMs/LSMs) and then calculating the range across GCMs (GHMs/LSMs). The quantile-based TWS index, spatially averaged over SREX regions, is calculated ${ }^{31}$ by (1) fitting a non-parametric kernel density function to TWS data, (2) estimating the PDF, and (3) numerically integrating the PDF between zero and the simulated TWS.

Component contribution of soil moisture to total TWS. A dimensionless metric, the component contribution ratio $\left(\mathrm{CCR}^{16,78}\right)$, is used to quantify the contribution of soil moisture to total TWS (Extended Data Fig. 6). CCR represents the ratio of seasonal amplitude of soil moisture to that of TWS. The CCR is used to assess the differences between the drought projected by TWS-DSI and soil moisture drought index (SMI). The contribution of other TWS components could not be examined as those variables are not currently available from ISIMIP $2 b$ simulations.

TWS Drought Severity Index (TWS-DSI) and drought severity under climate change. Monthly TWS drought severity index (TWS-DSI) is estimated for all ensemble members 
following Zhao et al. ${ }^{5} ; T W S-D S I_{i, j}=\left(T W S_{i, j}-\mu_{j}\right) / \sigma_{j}$, where $T W S_{i, j}$ is the TWS anomaly in year $i$ and month $j$, and $\mu_{j}$ and $\sigma_{j}$ are the climatological mean and standard deviation, respectively, of monthly TWS anomalies for the reference period. TWS-DSI $I_{i, j}$ is a nondimensional index that defines droughts with varying degrees of severity, also representing wet conditions (Supplementary Table 1). In calculating the mean and standard deviation of TWS for any specified period, a common reference period set to 1861-2099 is used to avoid potential exaggeration in the estimates of TWS variability and drought evolution ${ }^{79}$, and for consistent comparison. The drought trend (Figs. 4a-b) is calculated as the linear least-square trend using the time series of annual drought occurrence presented in days per year. The significance of trend values is evaluated using the non-parametric Mann-Kendall trend test ${ }^{80,81}$ with 5\% significance level. Note that for the trend calculations, four droughts types are re-grouped into two major categories for simplicity: moderate-to-severe $(-1.6<$ TWS-DSI $\leq-0.8)$ and extreme-toexceptional (TWS-DSI $\leq-1.6)$ droughts (see Supplementary Table 1 for more details).

The frequency of droughts with varying severities used for continental-scale drought analysis (Figs. 4c-h) is estimated by considering the TWS-DSI calculated for all ensemble members, normalized such that the results show the probability density function (PDF) at bins corresponding to the classes of drought and wet conditions (Supplementary Table 1). For the analysis of global population affected by drought, we use the time-varying (2006-2100) gridded global population data generated by scaling the 2005 population data from the Center for International Earth Science Information Network (CIESIN) at Columbia University (https://sedac.ciesin.columbia.edu/) with the country-level future population growth rate (https://tntcat.iiasa.ac.at/SspDb) for the Shared Socioeconomic Pathways 2 (SSP2) ${ }^{82}$. Among the five SSPs, SSP2 reflects an intermediate, middle of the road scenario in which population growth is medium ${ }^{83}$. The changes in future population under drought are estimated relative to the baseline period of 1976-2005 but using static population data for 2005. Finally, the PDFs for each IPCC SREX regions (Fig. 5) are estimated using the non-parametric kernel-density method $^{84}$ and by considering all ensemble members. There is a bimodality in the PDF of TWSDSI in some regions as a result of preferential states in water stores such as soil moisture ${ }^{85,86}$, thus using the non-parametric kernel-density method is more apt compared to the parametric unimodal distributions with underlying assumptions such as normality ${ }^{27,31}$. We find that using kernel-density method to estimate the PDF of TWS-DSI results in almost identical PDF estimation (not shown) to that from the conventional standardized drought indices ${ }^{29}-$ i.e., by first fitting the TWS data to a secondary distribution (e.g., gamma, Pearson Type III) and then transforming it to standard normal distribution.

The standardized precipitation index $\left(\mathrm{SPI}^{29}\right)$ and standardized runoff index $\left(\mathrm{SRI}^{33}\right)$ are calculated by first fitting the monthly precipitation and runoff data, respectively, to the gamma distribution function to obtain monthly climatological distributions for the reference period (1861-2099). These distributions are then used to estimate the cumulative probability of the variable (precipitation or runoff) for a certain period. Finally, the cumulative probabilities are converted to standard normal deviate ( $\mu=0$ and $\sigma=1$ ) by inversing the respective cumulative distribution function (CDF). The SMI is estimated based on two approaches. For the direct comparison with TWS-DSI, SMI is obtained using the same methodology as TWS-DSI ${ }^{5}$, however using soil 
moisture data instead of TWS (Extended Data Fig. 9). Additionally, a more conventional 611 quantile-based SMI (Extended Data Fig. 10) is calculated following Samaniego et al. ${ }^{31}$ and 612 Sheffield and Wood ${ }^{32}$. To do so, soil moisture is first fitted to a non-parametric kernel density 613 function to derive the monthly climatological PDFs for the reference period (1861-2099). The 614 quantile-based drought index corresponding to a given soil moisture for month $i\left(x_{i}\right)$ is then 615 derived by numerically integrating the respective $\operatorname{PDF}^{31}(\hat{f})$ as: $S M I_{i}=\int_{0}^{x_{i}} \hat{f}(u) d u$. The PDFs 616 of drought indices (SPI, SRI, and SMI) are generated for different periods using kernel-density 617 method (Extended Data Figs. 7-10).

\section{Data Availability}

620 The model results are freely available from the ISIMIP project portal

621 (https://www.isimip.org/outputdata/) and the two GRACE products used for model evaluation

622 can be obtained from http://www2.csr.utexas.edu/grace/ and https://podaac.jpl.nasa.gov/GRACE.

623 The processed data used to generate the figures in the main text are available on CUAHSI

624 HydroShare and Figshare (DOI: 10.6084/m9.figshare.13218710).

\section{Code Availability}

All figures are produced using the freely available visualization libraries in Python 3.5 (such as Matplotlib), and statistical analysis is performed using built-in functions in Python 3.5. The relevant portions of the computer code used to process the results and develop the figures are available at https://doi.org/10.5281/zenodo.4266999.

\section{References}

51 Haddeland, I. et al. Multimodel Estimate of the Global Terrestrial Water Balance: Setup and First Results. Journal of Hydrometeorology 12, 869-884, doi:10.1175/2011JHM1324.1 (2011).

52 Burek, P. et al. Development of the Community Water Model (CWatM v1.04) A high-resolution hydrological model for global and regional assessment of integrated water resources management. Geosci. Model Dev. Discuss. 2019, 1-49, doi:10.5194/gmd-2019-214 (2019).

53 Hanasaki, N. et al. An integrated model for the assessment of global water resources - Part 1: Model description and input meteorological forcing. Hydrol. Earth Syst. Sci. 12, 1007-1025, doi:10.5194/hess-12-1007-2008 (2008).

54 Hanasaki, N. et al. An integrated model for the assessment of global water resources - Part 2: Applications and assessments. Hydrol. Earth Syst. Sci. 12, 1027-1037, doi:10.5194/hess-12-10272008 (2008).

55 Stacke, T. \& Hagemann, S. Development and evaluation of a global dynamical wetlands extent scheme. Hydrol. Earth Syst. Sci. 16, 2915-2933, doi:10.5194/hess-16-2915-2012 (2012).

56 Wada, Y., Wisser, D. \& Bierkens, M. F. P. Global modeling of withdrawal, allocation and consumptive use of surface water and groundwater resources. Earth Syst. Dynam. 5, 15-40, doi:10.5194/esd-5-15-2014 (2014).

57 Mueller Schmied, H. et al. Variations of global and continental water balance components as impacted by climate forcing uncertainty and human water use. Hydrology and Earth System Sciences 20, 2877-2898 (2016).

58 Oleson, K. W. Technical Description of version 4.5 of the Community Land Model (CLM). 422 (National Center for Atmospheric Research, Boulder, CO, 2013). 
Bondeau, A. et al. Modelling the role of agriculture for the 20th century global terrestrial carbon balance. Global Change Biology 13, 679-706, doi:10.1111/j.1365-2486.2006.01305.x (2007). Lange, S. Trend-preserving bias adjustment and statistical downscaling with ISIMIP3BASD (v1. 0). Geoscientific Model Development 12, 3055-3070 (2019). Hempel, S., Frieler, K., Warszawski, L., Schewe, J. \& Piontek, F. A trend-preserving bias correction-the ISI-MIP approach. Earth System Dynamics 4, 219-236 (2013).

62 Lange, S. Bias correction of surface downwelling longwave and shortwave radiation for the EWEMBI dataset. Earth System Dynamics 9, 627-645 (2018).

63 Taylor, K. E., Stouffer, R. J. \& Meehl, G. A. An Overview of CMIP5 and the Experiment Design. Bull. Amer. Meteor. Soc. 93, 485-498, doi:10.1175/BAMS-D-11-00094.1 (2012).

64 Klein Goldewijk, K., Beusen, A., van Drecht, G. \& de Vos, M. The HYDE 3.1 spatially explicit database of human-induced global land-use change over the past 12,000 years. Global Ecology and Biogeography 20, 73-86, doi:10.1111/j.1466-8238.2010.00587.x (2011).

65 Portmann, F. T., Siebert, S. \& Döll, P. MIRCA2000 - Global monthly irrigated and rainfed crop areas around the year 2000: A new high-resolution data set for agricultural and hydrological modeling. Global Biogeochem. Cycles 24, GB1011, doi:10.1029/2008GB003435 (2010).

66 Ramankutty, N., Evan, A. T., Monfreda, C. \& Foley, J. A. Farming the planet: 1. Geographic distribution of global agricultural lands in the year 2000. Global Biogeochem. Cycles 22, GB1003, doi:10.1029/2007GB002952 (2008).

67 Lehner, B. et al. High-resolution mapping of the world's reservoirs and dams for sustainable river-flow management. Frontiers in Ecology and the Environment 9, 494-502, doi:10.1890/100125 (2011).

68 Hanasaki, N., Kanae, S. \& Oki, T. A reservoir operation scheme for global river routing models. Journal of Hydrology 327, 22-41, doi:10.1016/j.jhydrol.2005.11.011 (2006).

69 Biemans, H. et al. Impact of reservoirs on river discharge and irrigation water supply during the 20th century. Water Resources Research 47, W03509, doi:10.1029/2009WR008929 (2011).

70 Haddeland, I., Skaugen, T. \& Lettenmaier, D. P. Anthropogenic impacts on continental surface water fluxes. Geophysical Research Letters 33, L08406, doi:10.1029/2006GL026047 (2006).

71 Adam, J. C., Haddeland, I., Su, F. \& Lettenmaier, D. P. Simulation of reservoir influences on annual and seasonal streamflow changes for the Lena, Yenisei, and Ob' rivers. J. Geophys. Res. Atmos. 112, D24114, doi:10.1029/2007JD008525 (2007).

72 Eyring, V. et al. Taking climate model evaluation to the next level. Nature Climate Change, 1 (2019).

73 Wuttke, J. Laplace-Fourier transform of the stretched exponential function: Analytic error bounds, double exponential transform, and open-source implementation "libkww". Algorithms $\mathbf{5}$, 604-628 (2012).

74 Pokhrel, Y., Fan, Y., Miguez-Macho, G., Yeh, P. J. F. \& Han, S.-C. The role of groundwater in the Amazon water cycle: 3. Influence on terrestrial water storage computations and comparison with GRACE. J. Geophys. Res. Atmos. 118, 3233-3244, doi:10.1002/jgrd.50335 (2013).

75 Hirschi, M., Seneviratne, S. I. \& Schär, C. Seasonal variations in terrestrial water storage for major midlatitude river basins. Journal of Hydrometeorology 7, 39-60 (2006).

76 Scanlon, B. R. et al. Global evaluation of new GRACE mascon products for hydrologic applications. Water Resources Research 52, $9412-9429$ (2016).

77 Samaniego, L. et al. Propagation of forcing and model uncertainties on to hydrological drought characteristics in a multi-model century-long experiment in large river basins. Climatic Change 141, 435-449 (2017).

78 Kim, H., Yeh, P. J. F., Oki, T. \& Kanae, S. Role of rivers in the seasonal variations of terrestrial water storage over global basins. Geophysical Research Letters 36, L17402, doi:10.1029/2009GL039006 (2009).

79 Sippel, S. et al. Quantifying changes in climate variability and extremes: Pitfalls and their overcoming. Geophysical Research Letters 42, 9990-9998 (2015). 
80 Mann, H. B. Nonparametric tests against trend. Econometrica: Journal of the Econometric Society, 245-259 (1945).

81 Kendall, M. Rank correlation measures. Charles Griffin, London 202, 15 (1975).

82 Riahi, K. et al. The shared socioeconomic pathways and their energy, land use, and greenhouse gas emissions implications: an overview. Global Environmental Change 42, 153-168 (2017).

83 Knorr, W., Arneth, A. \& Jiang, L. Demographic controls of future global fire risk. Nature Climate Change 6, 781 (2016).

84 Gatrell, A. C., Bailey, T. C., Diggle, P. J. \& Rowlingson, B. S. Spatial point pattern analysis and its application in geographical epidemiology. Transactions of the Institute of British geographers, 256-274 (1996).

85 D'Odorico, P. \& Porporato, A. Preferential states in soil moisture and climate dynamics. PNAS 101, 8848-8851 (2004).

86 Laio, F., Porporato, A., Ridolfi, L. \& Rodriguez - Iturbe, I. On the seasonal dynamics of mean soil moisture. J. Geophys. Res. Atmos. 107, ACL 8-1-ACL 8-9 (2002).

\section{Acknowledgements}

Y.P. and F.F. acknowledge the support from the National Science Foundation (CAREER Award, grant \#: 1752729). H.M.S. and C.E.T. acknowledge the support from the German Federal Ministry of Education and Research (BMBF, grant \#: 01LS1711F). J.L. acknowledges the support from the Strategic Priority Research Program of Chinese Academy of Sciences (Grant No. XDA20060402), the National Natural Science Foundation of China (41625001, 51711520317). N.H. acknowledges the support from ERTDF (2RF-1802) of the ERCA, Japan. Y.W. is supported by the European Union under Horizon 2020 EUCP project (grant \#: 776613) and JPI Climate and European Union under ISIpedia project (grant \#: 690462). W.T.

acknowledges the support from the Uniscientia Foundation and the ETH Zurich Foundation (Fel45 15-1).

\section{Author contributions}

Y.P. conceived the research. F.F. processed model results, conducted the analyses, and prepared graphics. Y.P. and F.F. interpreted the results, and all authors discussed and commented on the outcome. Y.P. prepared the draft with contribution from F.F., and all authors commented on and edited the manuscript. Respective modelling groups conducted hydrological simulations under the ISIMIP2b project coordinated by S.N.G. and H.M.S.

\section{Competing interests}

The authors declare no competing interests.

\section{Additional Information}

Correspondence and requests for materials should be addressed to Y.P. 
Fig. 1 Impact of climate change on TWS. Shown are the changes (multi-model weighted mean) in TWS, averaged for the mid (2030-2059; $a$ and c) and late (2070-2099; b and d) twenty-first century under RCP 2.6 ( $a$ and b) and RCP 6.0 (c and d) relative to the average for the historical baseline period (19762005). Color hues show the magnitude of change and saturation indicates the agreement, among ensemble members, in the sign of change. The graph on the right of each panel shows the latitudinal mean.

Fig. 2 Uncertainty in TWS simulations. Shown are contributions of GCMs and GHMs/LSMs to the uncertainty in TWS simulations (the range statistic of quantile-based TWS index; see Methods), averaged over the sub-continental regions defined by the Intergovernmental Panel on Climate Change (IPCC) Special Report On Extremes (SREX; region description is provided in Supplementary Fig. 3). The horizontal axis denotes historical baseline period (1976-2005) and mid- (2030-2059) and late- (20702099) twenty-first century. A lighter color marks a smaller variability in TWS simulations across GCMs or GHMs/LSMs.

Fig. 3 Seasonal TWS variations averaged over the selected IPCC SREX regions. The seasonal cycle (weighted mean; same continental weights are used for all simulations) is estimated from the TWS time series for the respective periods (see legends), but the anomalies are calculated by using the mean for 1861-2099 period, generated by combining the results from HIST simulations with the corresponding RCP scenario. Labels and unit are shown in the inset for the entire globe. A description of SREX regions is provided in Supplementary Figure 3.

Fig. 4 | Projected changes in occurrence and time evolution of droughts under RCP6.0. The maps show the trend (days/year) in the frequency of moderate-to-severe (a) and extreme-to-exceptional (b) droughts for the 2006-2099 period. Single and double hatches show regions where $>50 \%$ and $>75 \%$ of the ensemble members, respectively, agree in the sign of change. Stippling marks regions where $>50 \%$ of ensemble members show a significant trend (Mann-Kendall test at 5\% significance level). The histograms on the right (c-h) show the frequency of droughts with varying severity indicated by monthly TWS-DSI on the X-axis (see Methods and Supplementary Tables 1 and 4), averaged over the continents for the baseline period (HIST; 1976-2005) and late-twenty-first century (2070-2099). The bottom panels present the change in fractional global land area (excluding Greenland, Antarctica) (i) and population projections under SSP2 (j) to experience moderate-to-severe (blue) and extreme-to-exceptional (red) droughts; shaded areas indicate \pm 1 standard deviation (SD) from the ensemble mean, representing the spread in the projection among ensemble members. Results for RCP2.6 are shown in the Supplementary Figure 4.

Fig. 5 | Probability density function of monthly TWS-DSI for the late-twenty-first century. Shown are ensemble simulations grouped for different cases (i.e., HIST, PIC, RCP2.6, and RCP6.0). Labels are indicated in the inset for the entire globe; $\mathrm{x}$-axis labels indicate TWS-DSI (Supplementary Table 1). A description of SREX regions (background map) is provided in Supplementary Figure 3. Similar results for the mid-twenty-first century are shown in Supplementary Figure 5. 
(a) Mid Century (RCP2.6)

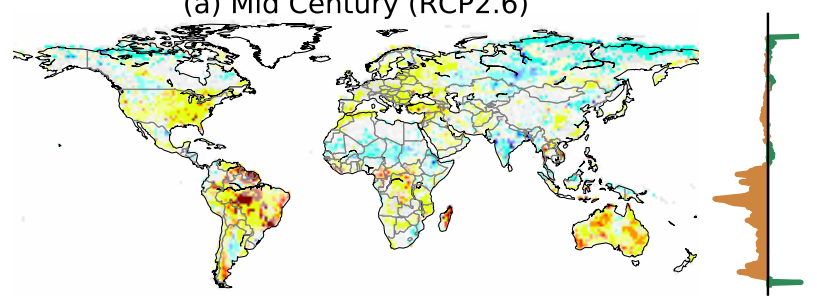

(c) Mid Century (RCP6.0)

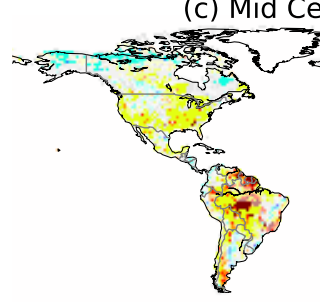

(b) Late Century (RCP2.6)

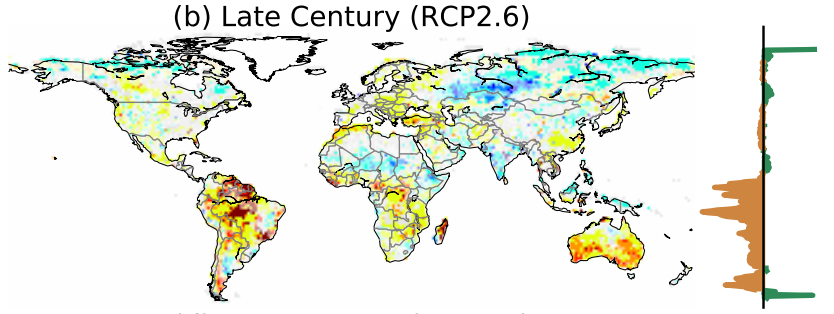

(d) Late Century (RCP6.0)

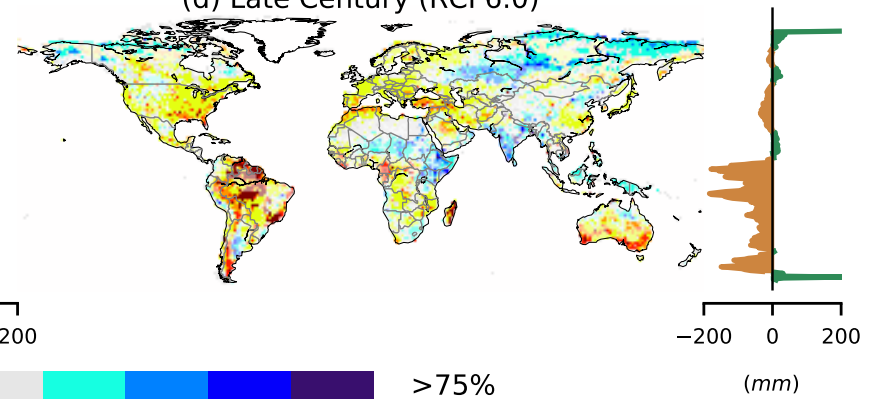

艺

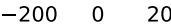

$50 \%-75 \%$ $<50 \%$ 


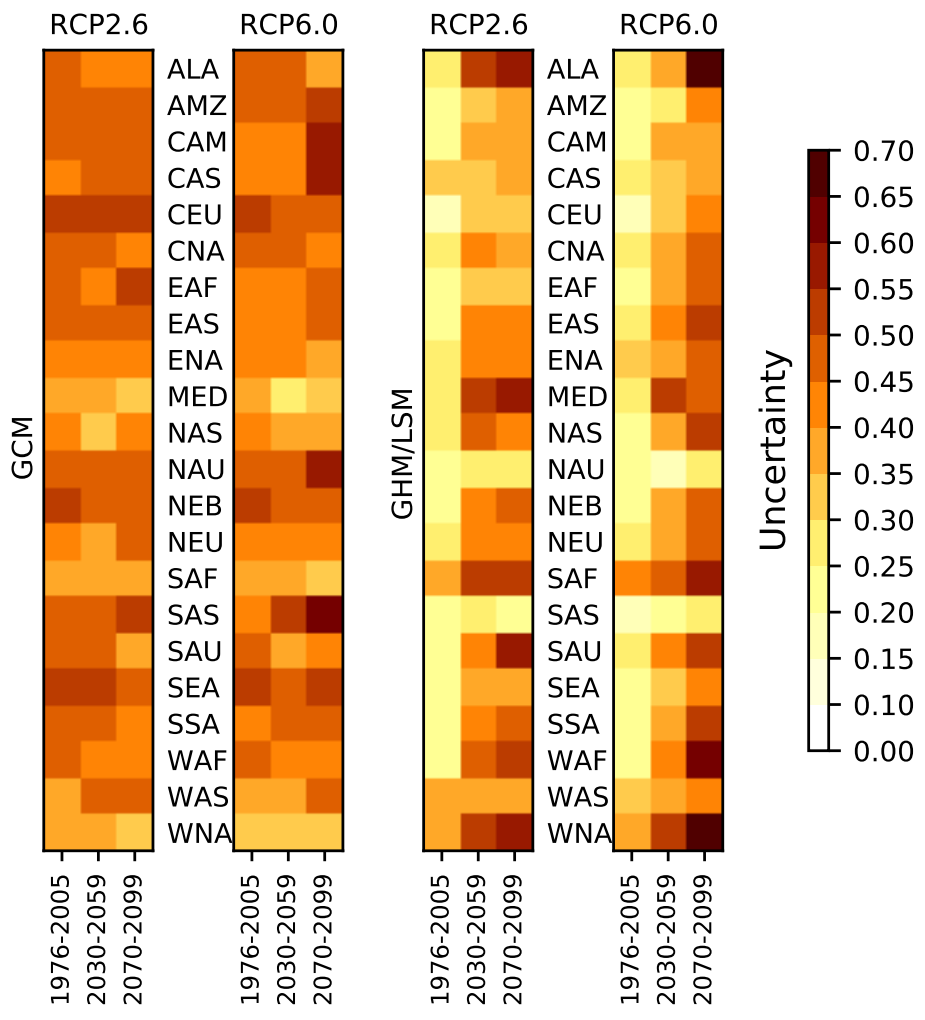




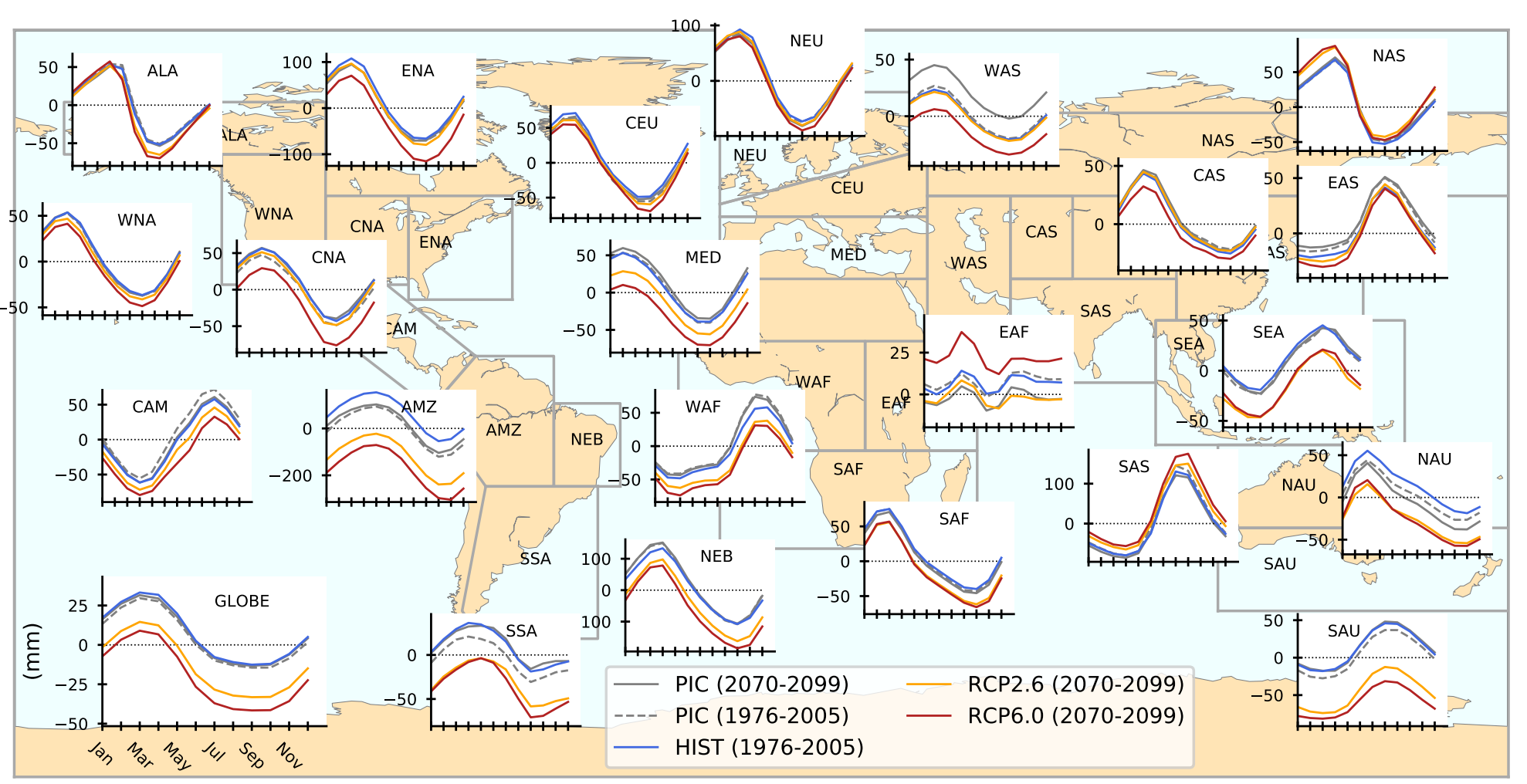


(a)
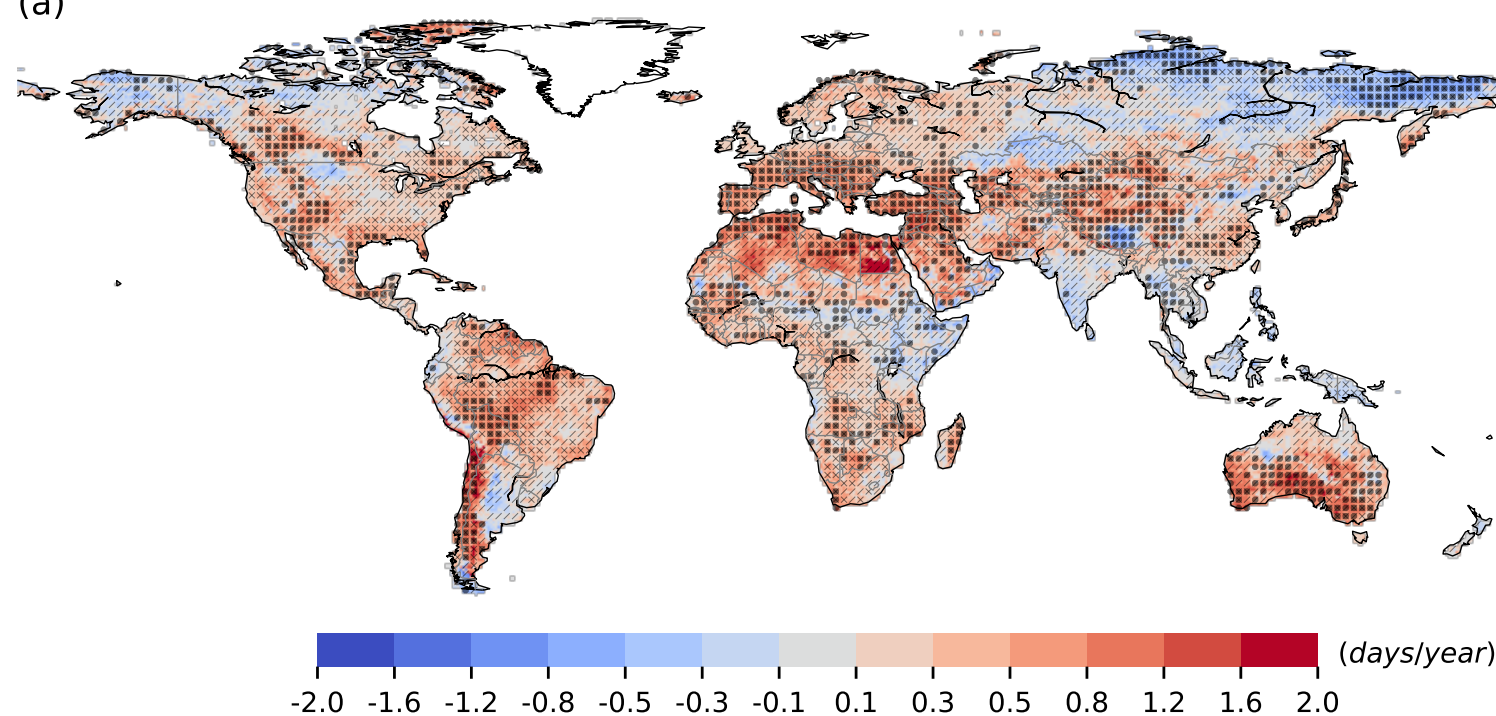

(b)
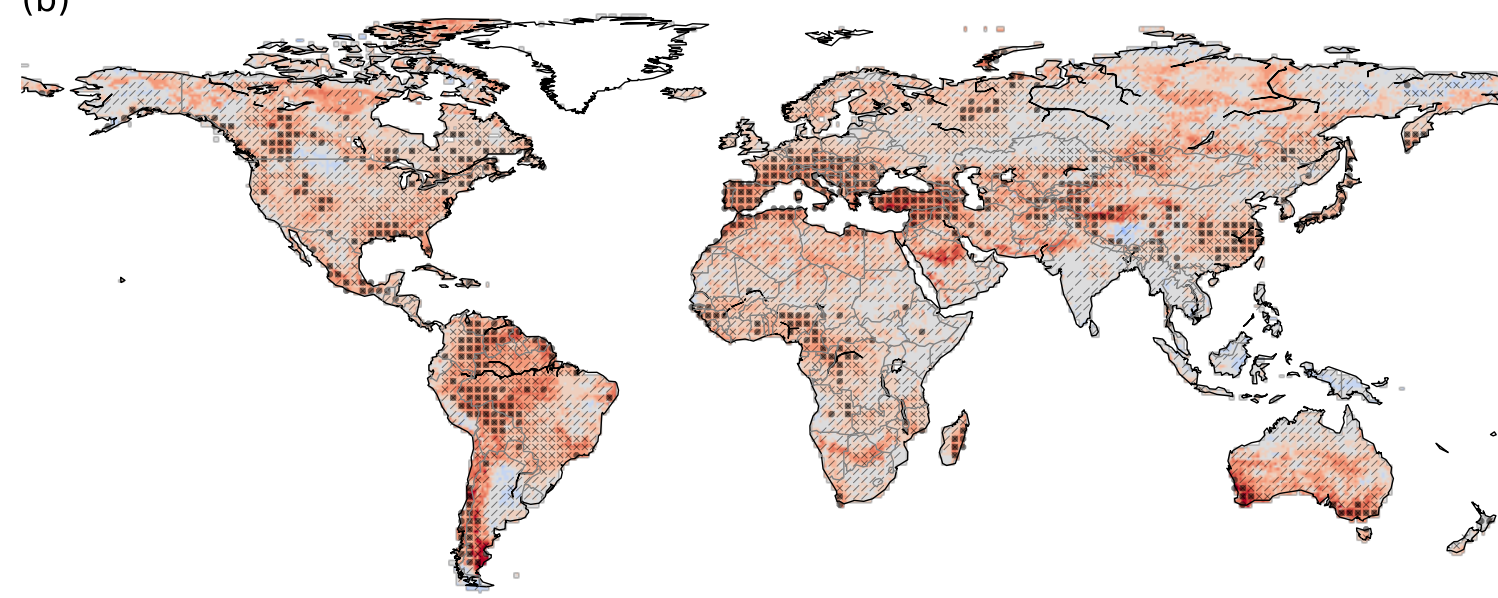

_ RCP6.0 Moderate-Severe

$\square \pm 1 S D$ RCP6.0 Extreme-Exceptional $\square \pm 1 S D$
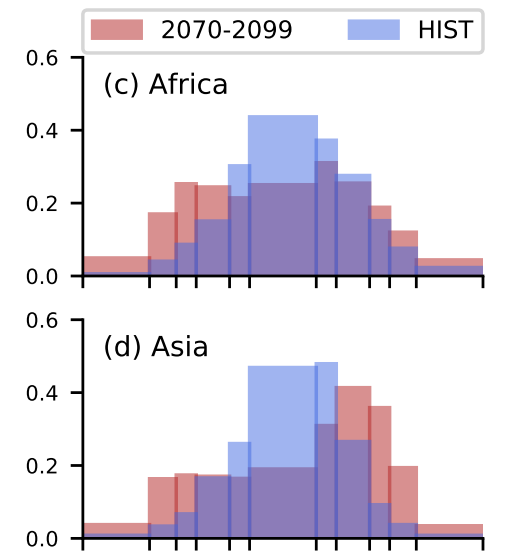

(e) Australia
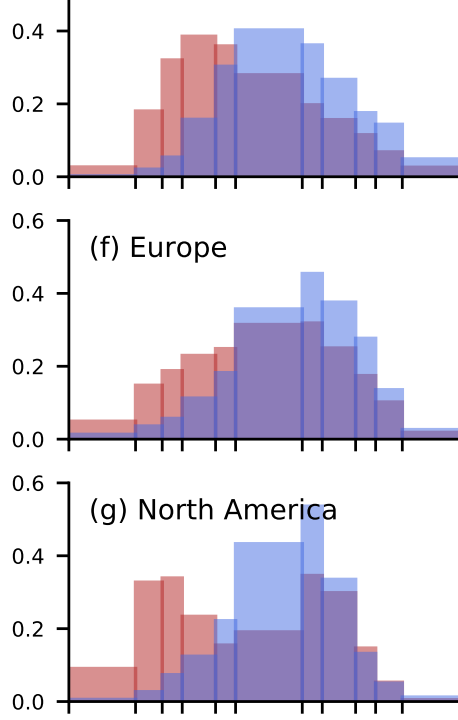

0.67 (h) South America

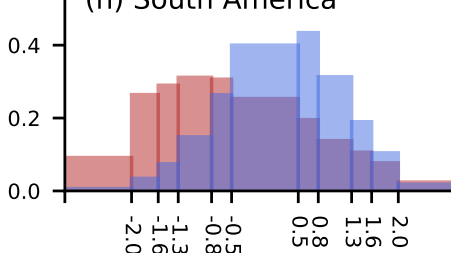

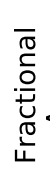

(i)

is

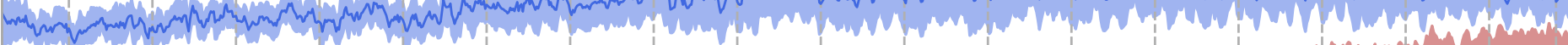
0.1 0.0 (1) : (j) 0.2 실.

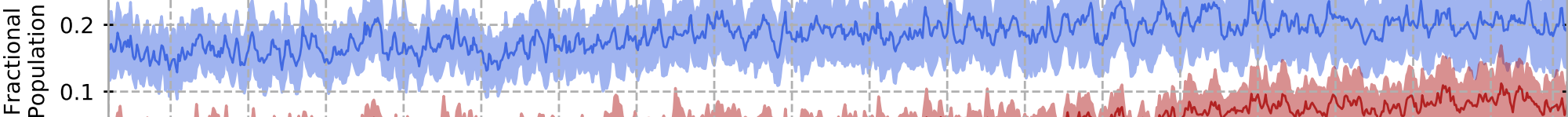
边 응 0.1 A 0.0 .

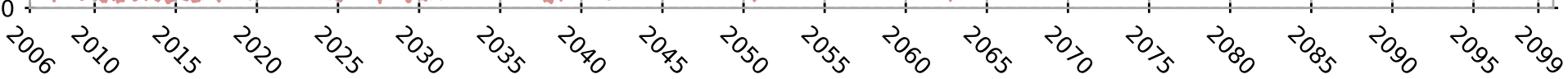




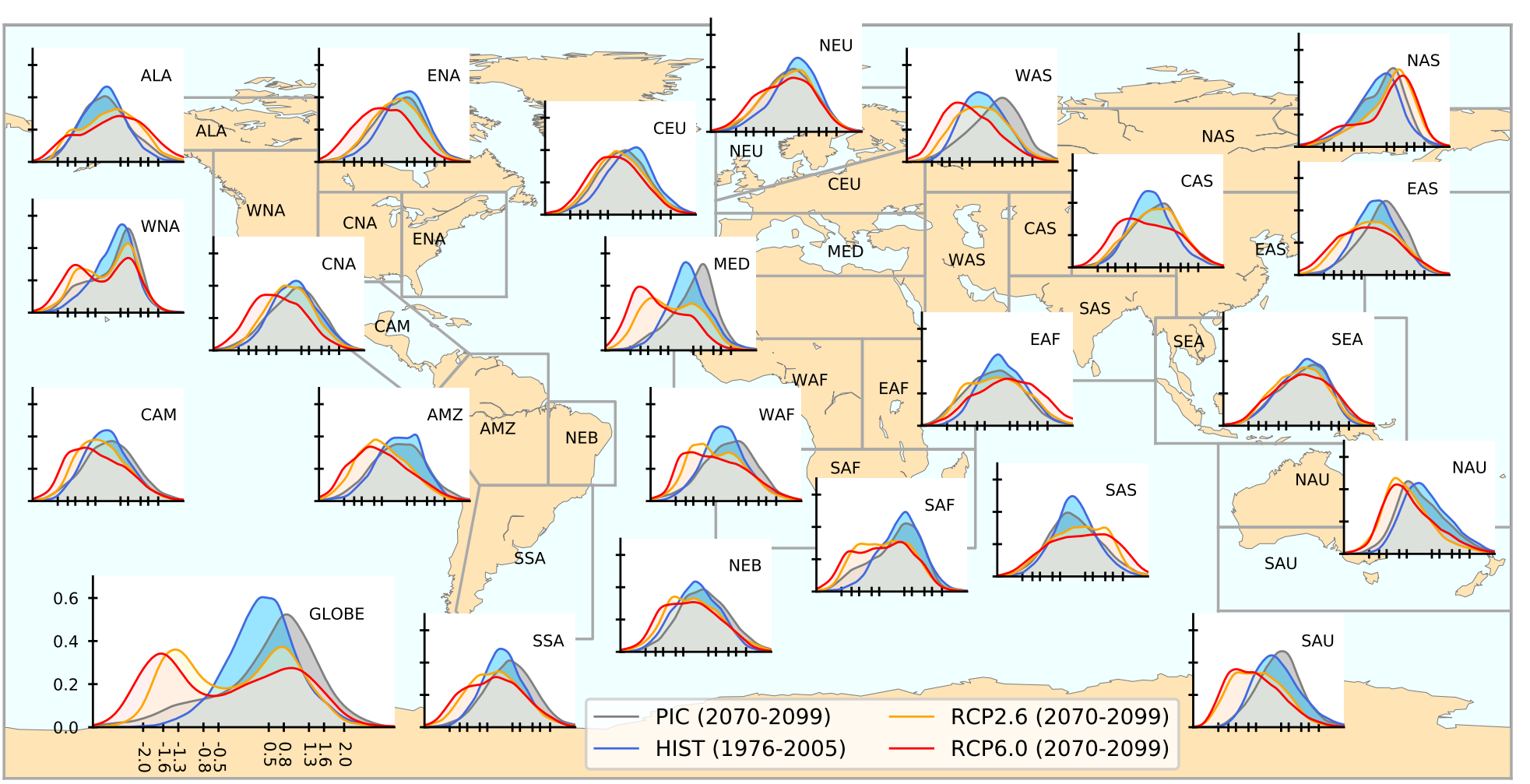


Asia

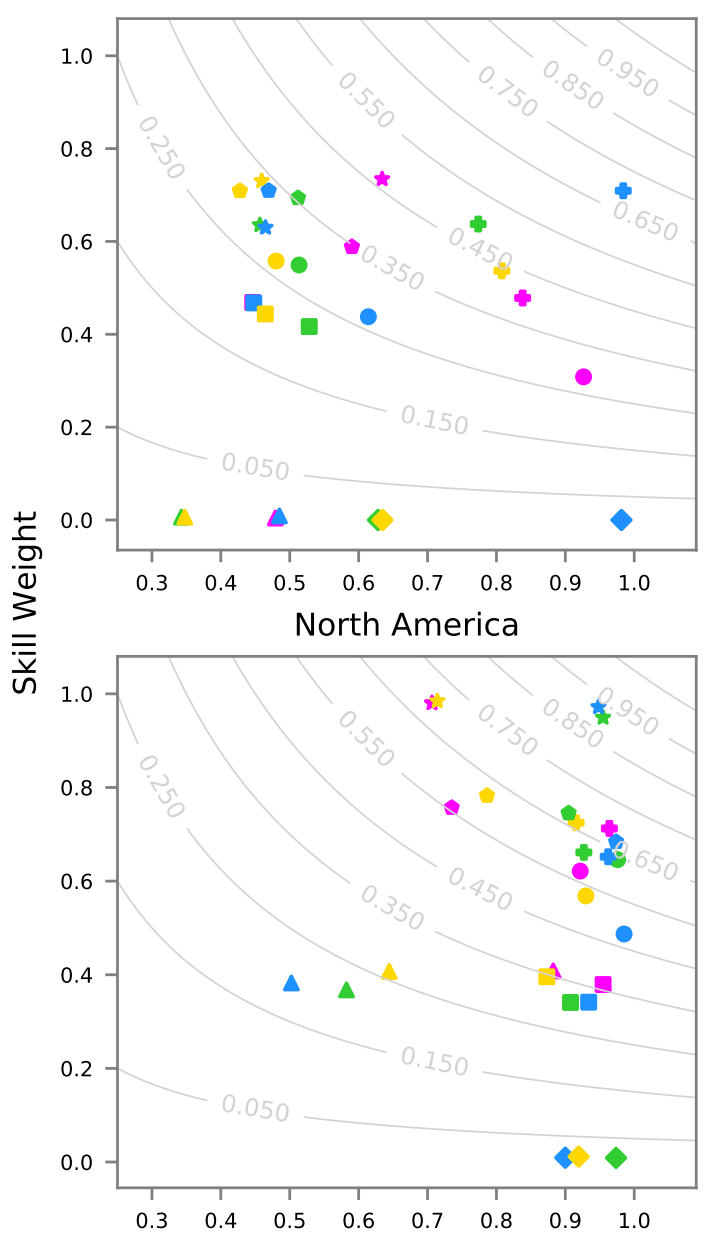

Europe
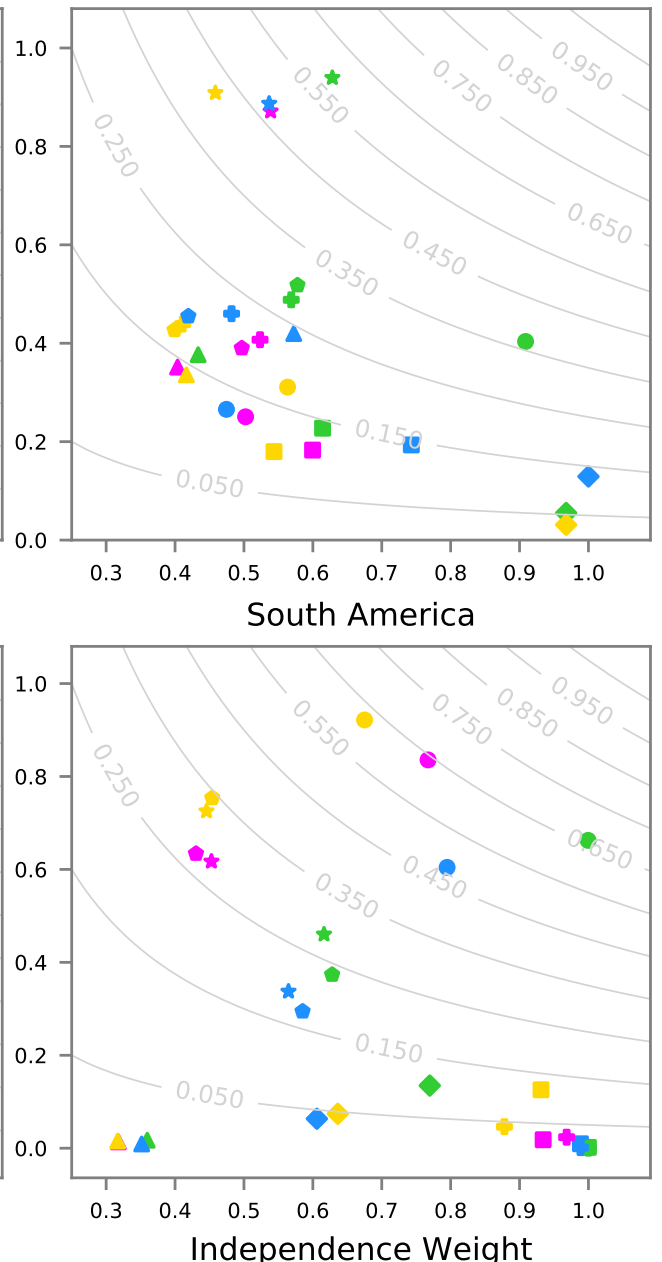

Africa

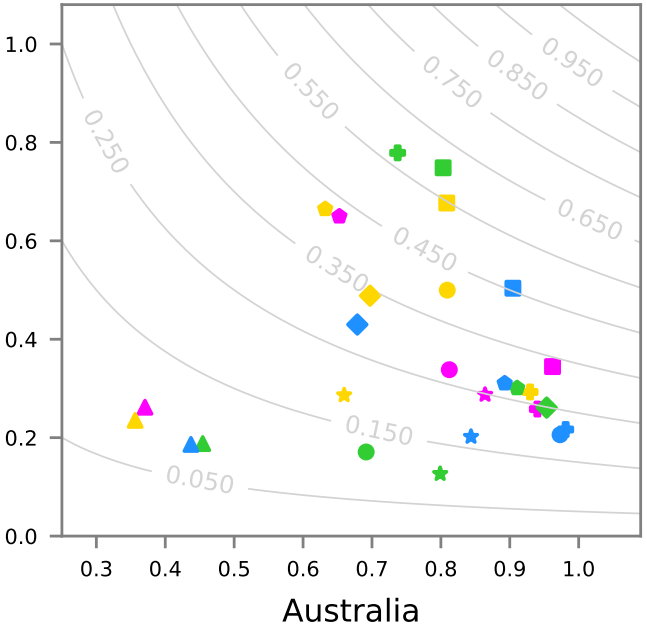

Australia

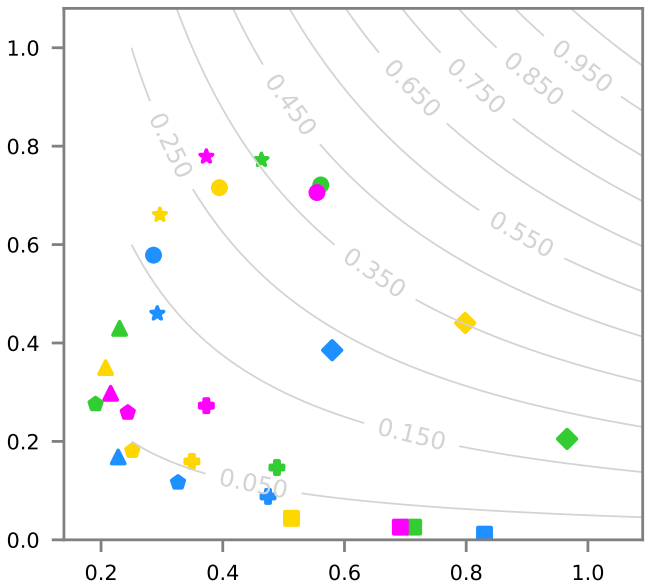

- clm45_gfdl-esm2m

- clm45_hadgem2-es

clm45_ipsl-cm5a-Ir clm45_miroc5
$\Delta \quad$ cwatm_gfdl-esm2m
- cwatm_hadgem2-es
- cwatm_ipsl-cm5a-Ir
$\Delta \quad$ cwatm_miroc5

- Ipjml_gfdl-esm2m $>$ mpi-hm_gfdl-esm $2 \mathrm{~m}$

- Ipjml_hadgem2-es

- Ipjml_ipsl-cm5a-Ir - Ipjml_miroc5 mpi-hm ipsl-cm5a-Ir mpi-hm_miroc5

\section{(n)_gfllesm $2 n$}

h08_hadgem2-es

- h08_miroc5 pcr-globwb_gfdl-esm2m

* pcr-globwb_hadgem2-es

* pcr-globwb_ipsl-cm5a-Ir * pcr-globwb_miroc5
- watergap2_gfdl-esm2m

- watergap2_hadgem2-es

- watergap2_ipsl-cm5a-Ir - watergap2_miroc5 
clm45_gfdl-esm $2 \mathrm{~m}$ -

clm45 hadgem2-es

clm45 ipsl-cm5a-Ir clm45_miroc5

Asia

\section{Europe}

cwatm_gfdl-esm $2 \mathrm{~m}$

cwatm hadgem2-es $\square \square$

cwatm ipsl-cm5a-Ir

cwatm_miroc5

h08_gfdl-esm $2 \mathrm{~m}$

h08_hadgem2-es $\square \square$

h08 ipsl-cm5a-Ir $\square$ h08 miroc5

Ipjml gfdl-esm2m

Ipjml hadgem2-es

Ipjmîipsl-cm5a-Ir Ipjml miroc5

mpi-hm gfdl-esm2m $\square \square \square \square \square \square \square$

mpi-hm_ipsl-cm5a-Ir

mpi-hm_miroc5 $\square \square \square \square$ pcr-globwb_gfdl-esm2m $2 m$ and pcr-globwb_hadgem2-es

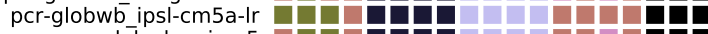
pcr-globwb_miroc5
a watergap2_gfdl-esm2m
watergap2_hadgem 2-es watergap2 ipsl-cm5a-Ir watergap2_miroc5

clm45_gfdl-esm $2 m$ -

clm45 hadgem2-es

clm45_ipsl-cm5a-Ir clm45_miroc5

cwatm_gfdl-esm2m 2 hadgem 2-es

cwatm_ipsl-cm5a-Ir $\square \square$ cwatm_miroc5 $\square \square \square$

h08_gfdl-esm $2 \mathrm{~m}$

h08_hadgem2-es $\square \square \square \square \square \square \square$

h08 ipsl-cm5a-Ir $\square \square \square \square \square \square$ h08 miroc5

Ipjml_gfdl-esm2m

Ipjml_hadgem2-es

Ipjmi ipsl-cm5a-Ir Ipjml miroc5 $\square \square \square \square \square \square \square \square \square \square \square \square \square$

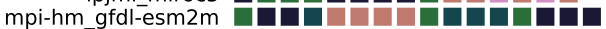

mpi-hm_ipsl-cm5a-Ir

mpi-hm_miroc5

pcr-globwb_gfdl-esm2m an

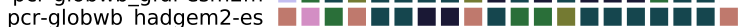

pcr-globwb ipsl-cm5a-Ir

pcr-globwb_miroc5

watergap2_gfdl-esm2m na

watergap2_hadgem2-es an a

watergap2 ipsl-cm5a-Ir $\square \square \square \square \square \square \square \square \square \square \square \square \square \square \square \square \square \square$

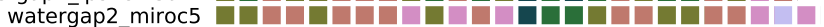

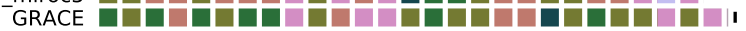

clm45 gfdl-esm2m -

clm45 hadgem2-es

clm45 ipsl-cm5a-Ir cIm45_miroc5

-

cwatm gfdl-esm $2 \mathrm{~m}$

cwatm hadgem2-es

cwatm ipsl-cm5a-Ir an cwatm_miroc5 $\square \square$

h08_gfdl-esm2m $2 \mathrm{~m}$

h08 hadgem2-es $\square \square \square \square \square$

h08 ipsl-cm5a-Ir $\square \square \square \square \square \square \square \square$ h08 miroc5 $\square$

Ipjml_gfdl-esm2m

Ipjml_hadgem2-es

Ipjmi ipsl-cm5a-Ir $\square \square \square \square \square \square \square \square$

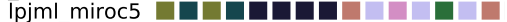

mpi-hm gfdl-esm $2 m$ m $\square \square \square \square \square \square \square \square$

mpi-hm_ipsl-cm5a-Ir $\square \square \square$ mpi-hm_miroc5 $\square \square \square \square$

pcr-globwb_gfdl-esm2m

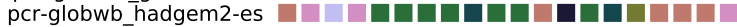

pcr-globwb ipsl-cm5a-Ir $\square \square \square \square \square \square \square \square \square \square \square \square$

pcr-globwb_miroc5

watergap2_gfdl-esm $2 \mathrm{~m}$ -

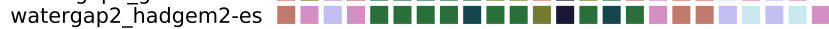

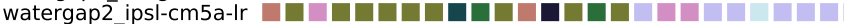

watergap2_miroc5

$$
\begin{aligned}
& \text { है }
\end{aligned}
$$

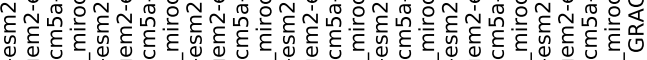

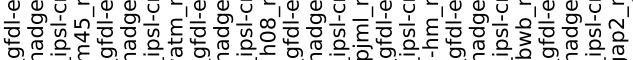

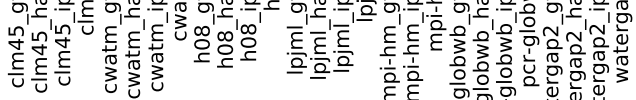

$$
\begin{aligned}
& \text { 就得 }
\end{aligned}
$$

2.5

2.0

1.5

1.2

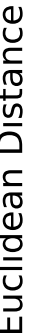

0.6

0.4

1.0

\section{In}

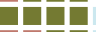

$+1$

ה日n

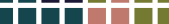

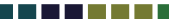

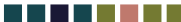

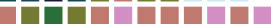

an

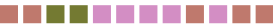

angannang

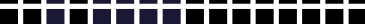

angangatata

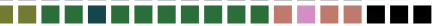

10

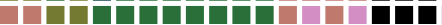

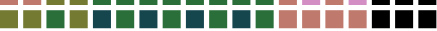

W

10

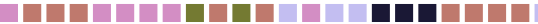

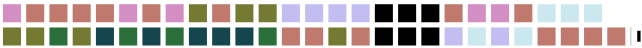

$-$

a

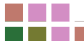

日+nt

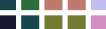

anamatrat

10日a

angana

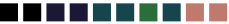

anmanama

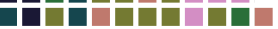

antantanta

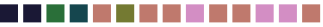

口n-

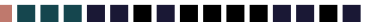

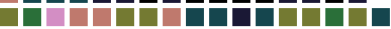

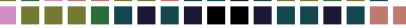

a

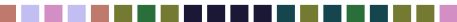

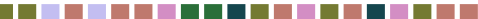

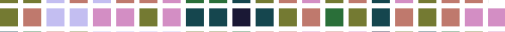

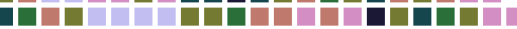

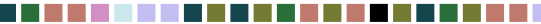

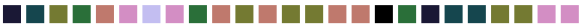

G

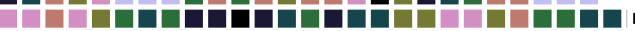

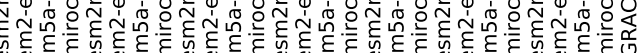

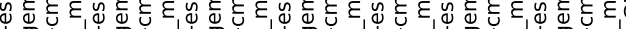

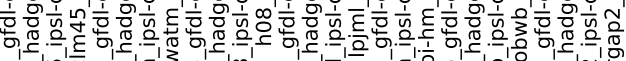

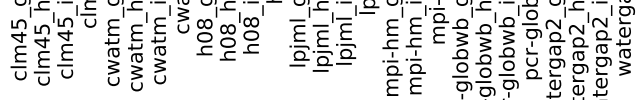

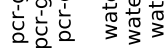


(a) Mid Century (RCP2.6)

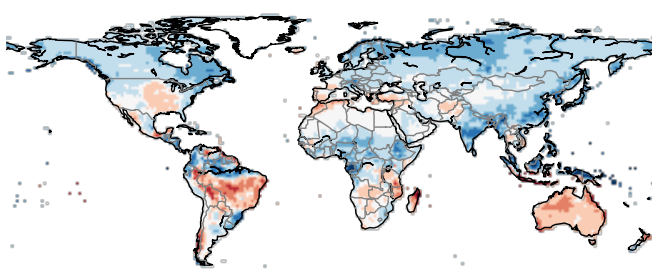

(c) Mid Century (RCP6.0)
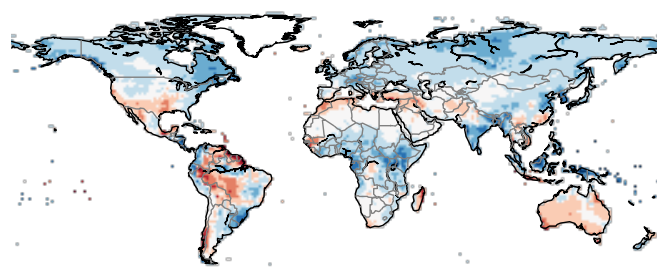

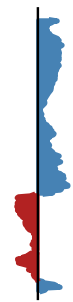

(b) Late Century (RCP2.6)

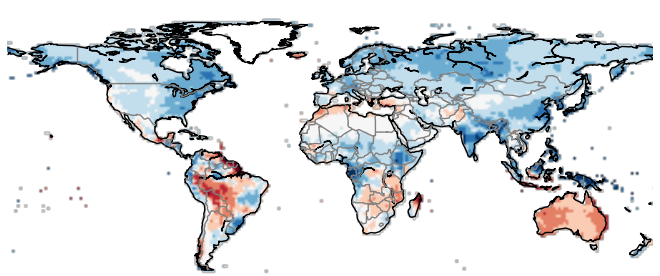

(d) Late Century (RCP6.0)
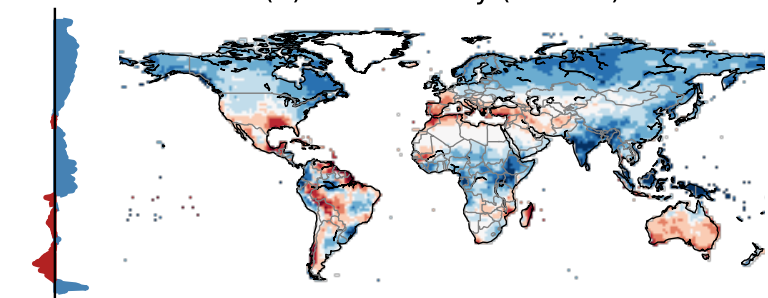

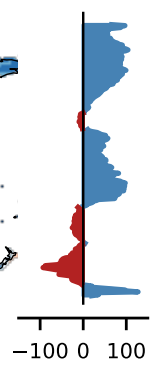

$(\mathrm{mm})$

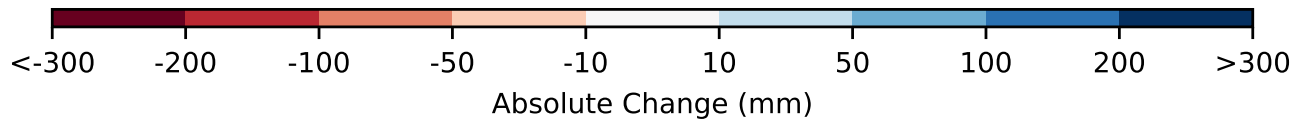


(a) Mid Century (RCP2.6)

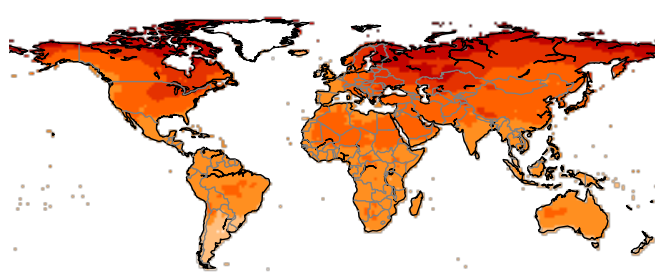

(c) Mid Century (RCP6.0)

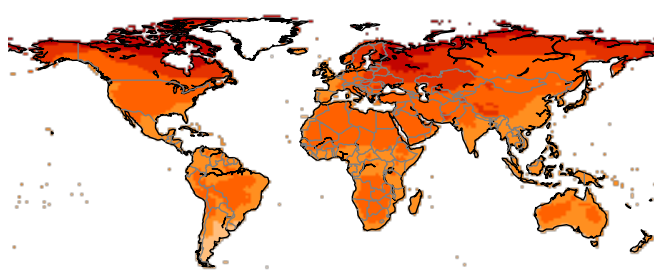

(b) Late Century (RCP2.6)
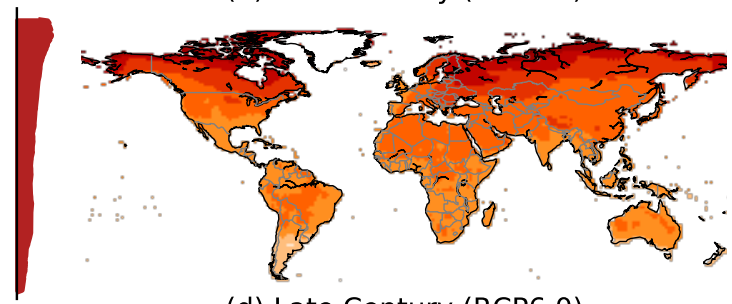

(d) Late Century (RCP6.0)

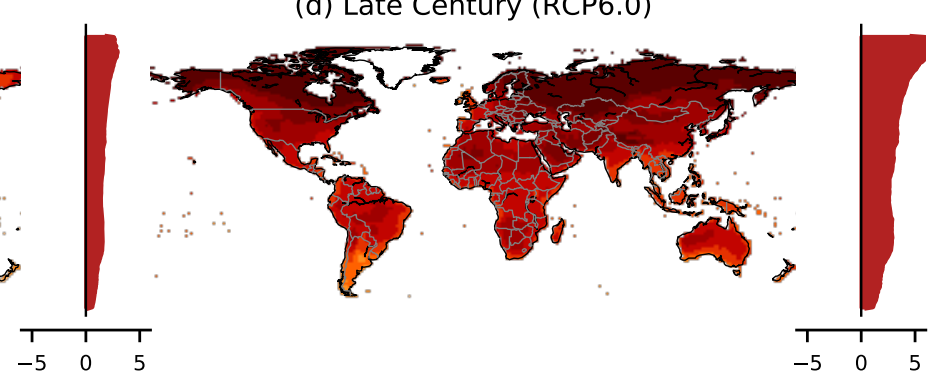

(K)

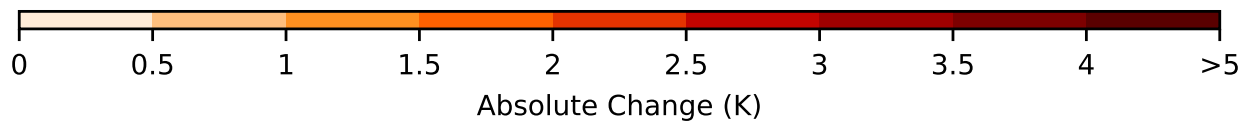


DJF (Unweighted Mean)

DJF (GRACE)

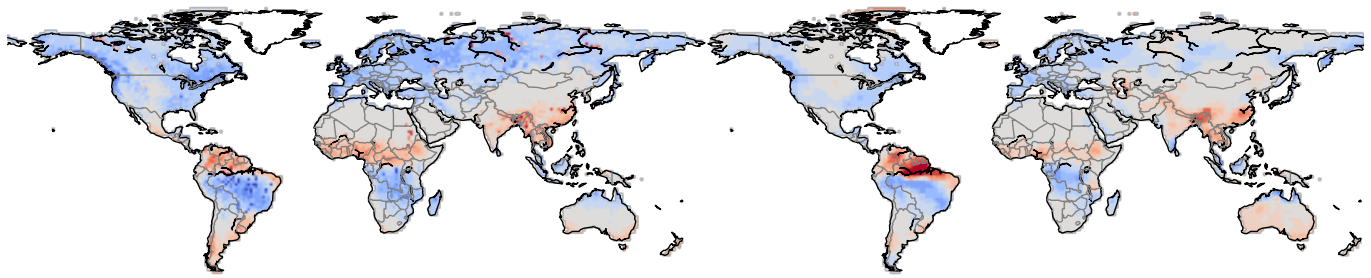

MAM (Unweighted Mean)

MAM (GRACE)

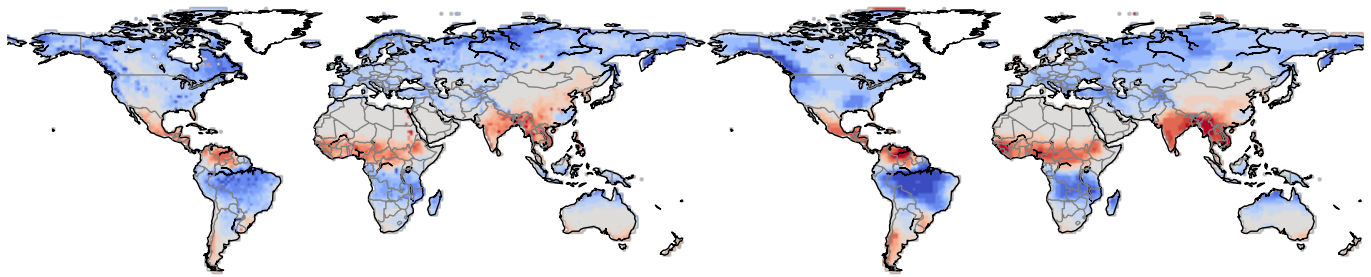

JJA (Unweighted Mean)

JJA (GRACE)

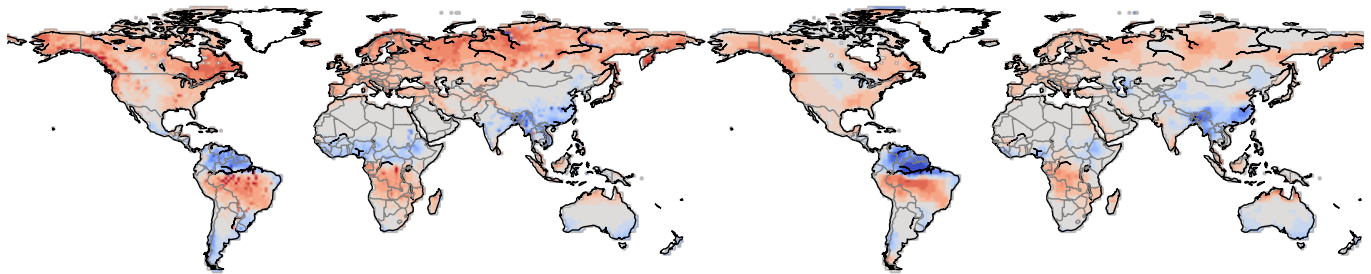

SON (Unweighted Mean)

SON (GRACE)
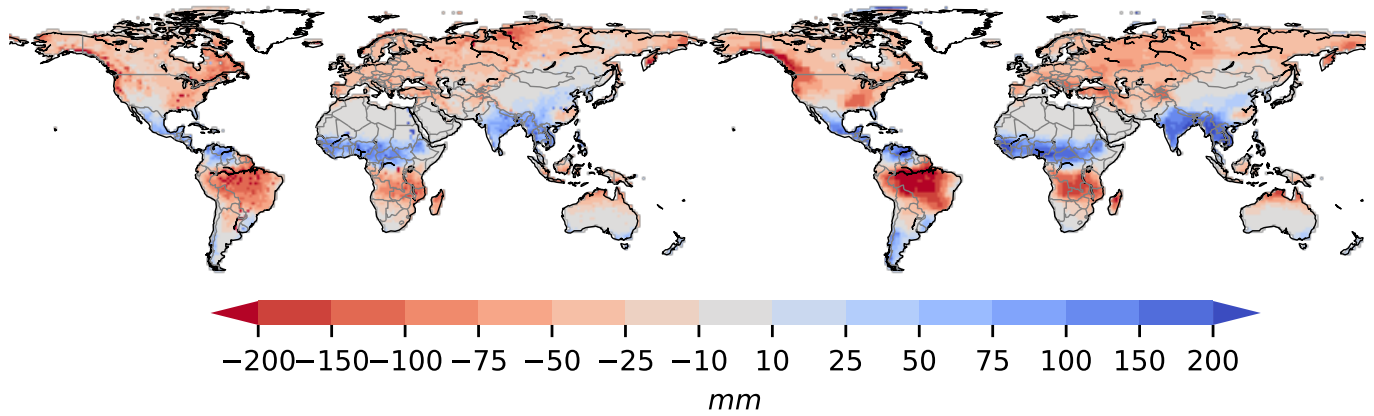


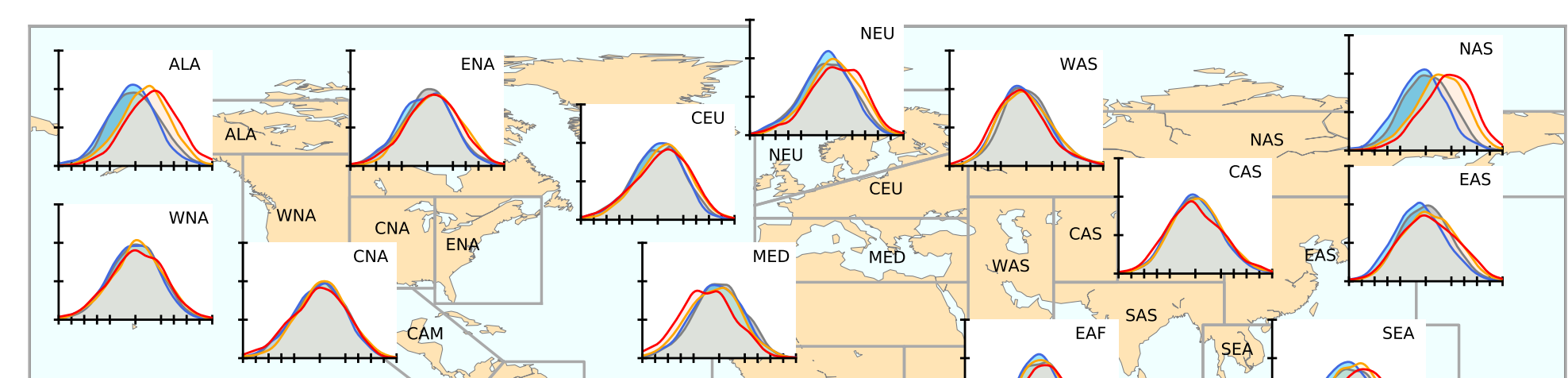

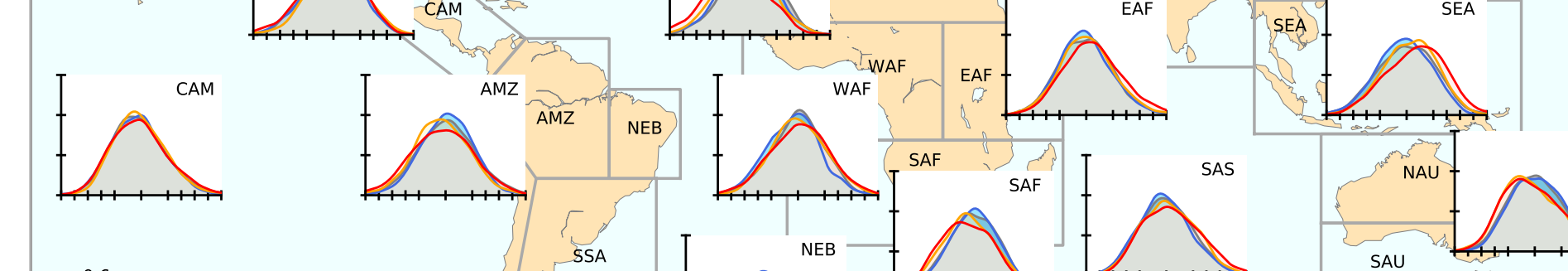

$$
\begin{aligned}
& H \Lambda^{-1} \omega^{2} u
\end{aligned}
$$




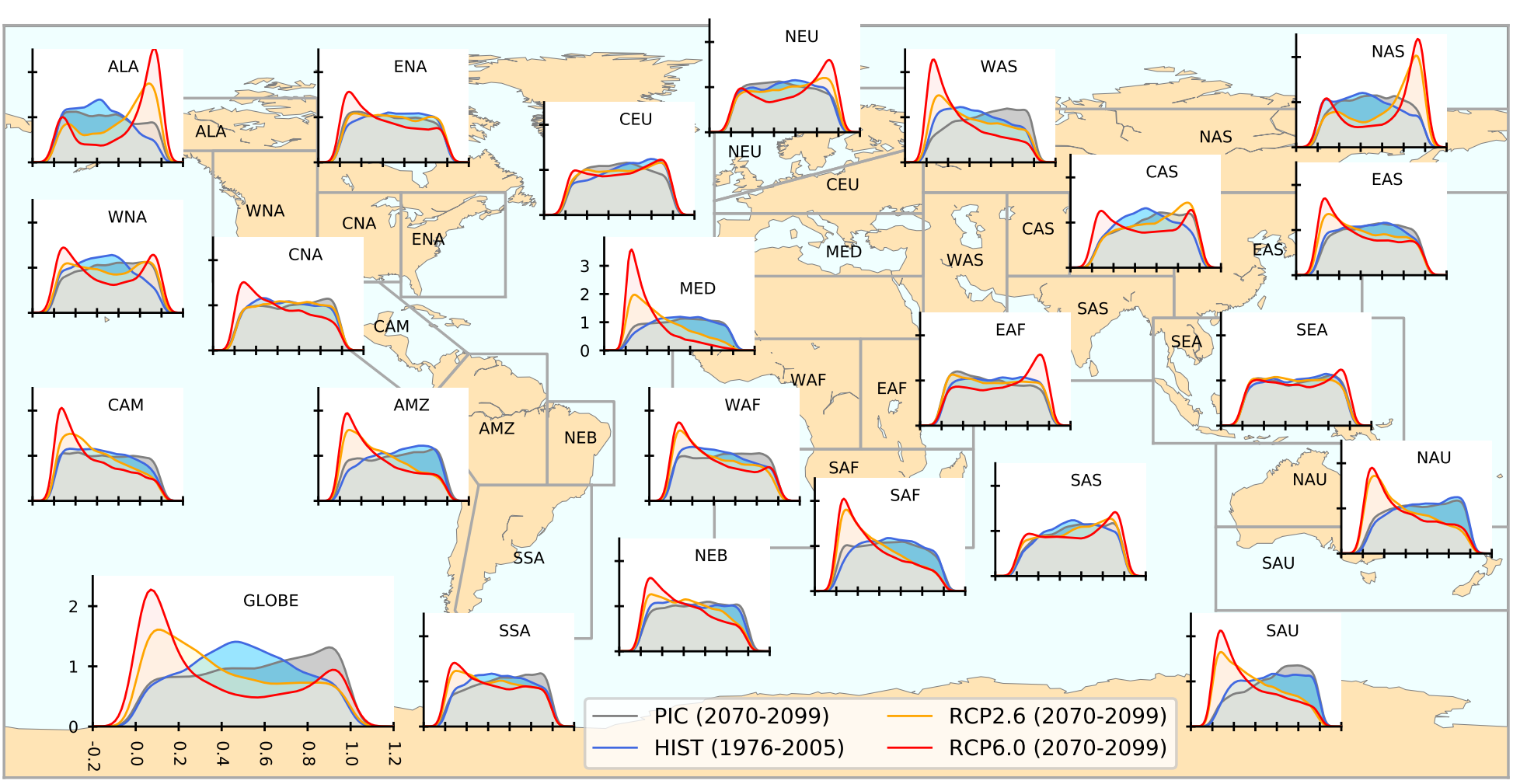




\section{SUPPLEMENTARY INFORMATION}

\section{Global Terrestrial Water Storage and Drought Severity under Climate Change}

Yadu Pokhrel $^{1 *}$, Farshid Felfelani ${ }^{1}$, Yusuke Satoh ${ }^{2}$, Julien Boulange ${ }^{2}$, Peter Burek ${ }^{3}$, Anne Gädeke $^{4}$, Dieter Gerten ${ }^{4,5}$, Simon N. Gosling ${ }^{6}$, Manolis Grillakis ${ }^{7}$, Lukas Gudmundsson ${ }^{8}$, Naota Hanasaki $^{2}$, Hyungjun Kim ${ }^{9}$, Aristeidis Koutroulis ${ }^{7}$, Junguo Liu ${ }^{10}$, Lamprini Papadimitriou ${ }^{11}$, Jacob Schewe ${ }^{4}$, Hannes Müller Schmied ${ }^{12,13}$, Tobias Stacke ${ }^{14}$, Camelia-Eliza Telteu ${ }^{12}$, Wim Thiery $^{15,8}$, Ted Veldkamp ${ }^{16,17}$, Fang Zhao ${ }^{18,4}$ and Yoshihide Wada ${ }^{3,17}$

${ }^{1}$ Department of Civil and Environmental Engineering, Michigan State University, East Lansing, MI, USA

${ }^{2}$ National Institute for Environmental Studies, Tsukuba, Japan

${ }^{3}$ International Institute for Applied Systems Analysis, Laxenburg, Austria

${ }^{4}$ Potsdam Institute for Climate Impact Research (PIK), Member of the Leibniz Association, Potsdam, Germany

${ }^{5}$ Humboldt-Universität zu Berlin, Berlin, Germany

${ }^{6}$ School of Geography, University of Nottingham, Nottingham, UK

${ }^{7}$ School of Environmental Engineering, Technical University of Crete, Chania, Greece

${ }^{8}$ Institute for Atmospheric and Climate Science, ETH Zurich, Zurich, Switzerland

${ }^{9}$ Institute of Industrial Science, the University of Tokyo, Tokyo, Japan

${ }^{10}$ School of Environmental Science and Engineering, Southern University of Science and Technology, Shenzhen, China

${ }^{11}$ Cranfield Water Science Institute (CWSI), Cranfield University, Cranfield, Bedfordshire, UK

${ }^{12}$ Institute of Physical Geography, Goethe-University Frankfurt, Frankfurt am Main, Germany

${ }^{13}$ Senckenberg Leibniz Biodiversity and Climate Research Centre Frankfurt (SBiK-F), Frankfurt am Main, Germany

${ }^{14}$ Institute of Coastal Research, Helmholtz-Zentrum Geesthacht (HZG),

Geesthacht, Germany

${ }^{15}$ Department of Hydrology and Hydraulic Engineering, Vrije Universiteit Brussel, Brussels, Belgium

${ }^{16}$ Department of Water \& Climate Risk, VU University, Amsterdam, the Netherlands

${ }^{17}$ Department of Physical Geography, Utrecht University, Utrecht, Netherlands

${ }^{18}$ School of Geographic Sciences, East China Normal University, Shanghai, China

*e-mail: ypokhrel@egr.msu.edu 


\section{Terrestrial water storage (TWS) drought severity index (TWS-DSI)}

Supplementary Table 1 | TWS drought severity index (TWS-DSI). The index values represent the range of relative categories of drought and wet conditions used to define drought severity ${ }^{1}$. For the calculation of drought trends, the four drought categories are grouped into two major drought types, namely the moderate-to-severe $(-1.6<$ TWS-DSI $\leq-0.8)$ and extreme-to-exceptional (TWS-DSI $\leq-1.6)$ droughts.

\begin{tabular}{|l|c|}
\hline Description & TWS-DSI Value \\
\hline Exceptional Drought & $\leq-2.0$ \\
\hline Extreme Drought & $-2.0<D S I \leq-1.6$ \\
\hline Severe Drought & $-1.6<D S I \leq-1.3$ \\
\hline Moderate Drought & $-1.3<D S I \leq-0.8$ \\
\hline Abnormally Dry & $-0.8<D S I \leq-0.5$ \\
\hline Near Normal & $-0.5<D S I<+0.5$ \\
\hline Slightly Wet & $+0.5 \leq D S I<+0.8$ \\
\hline Moderately Wet & $+0.8 \leq D S I<+1.3$ \\
\hline Very Wet & $+1.3 \leq D S I<+1.6$ \\
\hline Extremely Wet & $+1.6 \leq D S I<+2.0$ \\
\hline Exceptionally Wet & $\geq+2.0$ \\
\hline
\end{tabular}


2. Ensemble Simulations and Hydrology Models

Supplementary Table 2 | Summary of multi-model ensemble simulations.

\begin{tabular}{|c|c|c|c|c|c|c|c|c|}
\hline \multirow{3}{*}{ 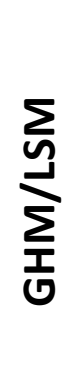 } & \multirow{3}{*}{\begin{tabular}{|} 
Radiative Forcing \\
Simulation Period \\
Socio-economic \\
Scenario
\end{tabular}} & \multicolumn{3}{|c|}{$\begin{array}{l}\text { Preindustrial Control } \\
\text { (PIC) }\end{array}$} & \multirow{2}{*}{\multicolumn{2}{|c|}{$\begin{array}{c}\begin{array}{c}\text { Historical } \\
\text { (HIST) }\end{array} \\
1861-2005 \\
\end{array}$}} & RCP2.6 & RCP6.0 \\
\hline & & \multicolumn{2}{|c|}{ 1861-2005 } & \multirow{2}{*}{ 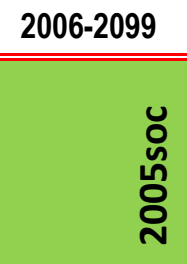 } & & & \multicolumn{2}{|c|}{ 2006-2099 } \\
\hline & & 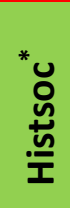 & 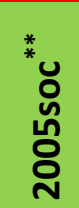 & & 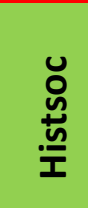 & ठั. & 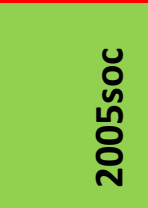 & 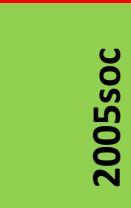 \\
\hline \multirow{4}{*}{$\sum_{j}^{\stackrel{n}{u}}$} & GFDL-ESM2M & & $\mathrm{x}$ & $\mathrm{x}$ & & $\mathrm{x}$ & $\mathrm{x}$ & $\mathrm{x}$ \\
\hline & HADGEM2-ES & & $x$ & $x$ & & $\mathrm{x}$ & $x$ & $x$ \\
\hline & IPSL-CM5A-LR & & $\mathrm{x}$ & $x$ & & $\mathrm{x}$ & $\mathrm{x}$ & $\mathrm{x}$ \\
\hline & MIROC5 & & $x$ & $x$ & & $\mathrm{x}$ & $x$ & $x$ \\
\hline \multirow{4}{*}{ 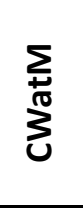 } & GFDL-ESM2M & $\mathrm{x}$ & & $\mathrm{x}$ & $\mathrm{x}$ & & $\mathrm{x}$ & $\mathrm{x}$ \\
\hline & HADGEM2-ES & $\mathrm{x}$ & & $\mathrm{x}$ & $\mathrm{x}$ & & $\mathrm{x}$ & $\mathrm{x}$ \\
\hline & IPSL-CM5A-LR & $\mathrm{x}$ & & $\mathrm{x}$ & $\mathrm{x}$ & & $\mathrm{x}$ & $\mathrm{x}$ \\
\hline & MIROC5 & $x$ & & $\mathrm{x}$ & $\mathrm{x}$ & & $x$ & $\mathrm{x}$ \\
\hline \multirow{4}{*}{ : } & GFDL-ESM2M & $\mathrm{x}$ & & $\mathrm{x}$ & $\mathrm{x}$ & & $\mathrm{x}$ & $\mathrm{x}$ \\
\hline & HADGEM2-ES & $\mathrm{x}$ & & $\mathrm{x}$ & $\mathbf{x}$ & & $\mathbf{x}$ & $\mathbf{x}$ \\
\hline & IPSL-CM5A-LR & $\mathrm{x}$ & & $\mathrm{x}$ & $\mathrm{x}$ & & $\mathrm{x}$ & $\mathrm{x}$ \\
\hline & MIROC5 & $\mathrm{x}$ & & $\mathrm{x}$ & $\mathrm{x}$ & & $\mathrm{x}$ & $\mathrm{x}$ \\
\hline \multirow{4}{*}{$\frac{\vec{\xi}}{\stackrel{1}{a}}$} & GFDL-ESM2M & $\mathrm{x}$ & & $\mathrm{x}$ & $\mathrm{x}$ & & $x$ & $\mathrm{x}$ \\
\hline & HADGEM2-ES & $\mathrm{x}$ & & $\mathrm{x}$ & $\mathrm{x}$ & & $\mathrm{x}$ & $\mathrm{x}$ \\
\hline & IPSL-CM5A-LR & $x$ & & $x$ & $x$ & & $x$ & $x$ \\
\hline & MIROC5 & $x$ & & $x$ & $x$ & & $x$ & $x$ \\
\hline \multirow{4}{*}{$\frac{\sum}{\frac{1}{1}}$} & GFDL-ESM2M & $x$ & & $x$ & $x$ & & $x$ & $x$ \\
\hline & HADGEM2-ES & \multicolumn{7}{|c|}{ Not Available } \\
\hline & IPSL-CM5A-LR & $\mathrm{x}$ & & $\mathrm{x}$ & $\mathrm{x}$ & & $\mathrm{x}$ & $\mathrm{x}$ \\
\hline & MIROC5 & $\mathrm{x}$ & & $\mathrm{x}$ & $\mathrm{x}$ & & $\mathrm{x}$ & $\mathrm{x}$ \\
\hline \multirow{4}{*}{ 它塄 } & GFDL-ESM2M & $\mathrm{x}$ & & $\mathrm{x}$ & $\mathrm{x}$ & & $\mathrm{x}$ & $\mathrm{x}$ \\
\hline & HADGEM2-ES & $x$ & & $x$ & $x$ & & $x$ & $x$ \\
\hline & IPSL-CM5A-LR & $x$ & & $x$ & $x$ & & $x$ & $x$ \\
\hline & MIROC5 & $x$ & & $x$ & $\mathrm{x}$ & & $x$ & $\mathrm{x}$ \\
\hline \multirow{4}{*}{ 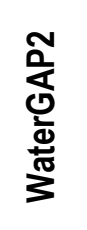 } & GFDL-ESM2M & $\mathrm{x}$ & & $\mathrm{x}$ & $\mathrm{x}$ & & $\mathrm{x}$ & $\mathrm{x}$ \\
\hline & HADGEM2-ES & $\mathrm{x}$ & & $\mathrm{x}$ & $\mathrm{x}$ & & $x$ & $\mathrm{x}$ \\
\hline & IPSL-CM5A-LR & $\mathrm{x}$ & & $\mathrm{x}$ & $\mathrm{x}$ & & $\mathrm{x}$ & $\mathrm{x}$ \\
\hline & MIROC5 & $x$ & & $x$ & $x$ & & $x$ & $x$ \\
\hline
\end{tabular}

*Histsoc: time-varying, historical socio-economic scenarios.

**2005soc: socio-economic scenarios fixed at 2005 level. 
Supplementary Table 3 | Details of models used in this study.

\begin{tabular}{|c|c|c|c|c|c|c|c|c|c|}
\hline Models & $\begin{array}{l}\text { Model } \\
\text { Type }\end{array}$ & $\begin{array}{l}\text { Evapotranspiration } \\
\text { Scheme }\end{array}$ & Snow Scheme & $\begin{array}{l}\text { Groundwater } \\
\text { Scheme }\end{array}$ & $\begin{array}{l}\text { Runoff Scheme } \\
\text { (Surface Runoff/ } \\
\text { Subsurface } \\
\text { Runoff) } \\
\end{array}$ & $\begin{array}{l}\text { River Routing } \\
\text { Scheme }\end{array}$ & $\begin{array}{l}\text { Reservoir } \\
\text { Operation }\end{array}$ & $\begin{array}{l}\text { Human Water } \\
\text { Use }\end{array}$ & References \\
\hline CLM4.5 & LSM $^{\mathrm{a}}$ & $\begin{array}{l}\text { Monin-Obukhov } \\
\text { Similarity Theory }\end{array}$ & $\begin{array}{l}\text { Physically } \\
\text { based snow } \\
\text { module }\end{array}$ & $\begin{array}{l}\text { Explicit (single } \\
\text { reservoir) }\end{array}$ & $\begin{array}{l}\text { Infiltration excess } \\
\text { and saturation } \\
\text { excess, } \\
\text { groundwater } \\
\text { discharge }\end{array}$ & $\begin{array}{l}\text { River Transport } \\
\text { Model }\end{array}$ & No & Irrigation & Refs. $^{2,3}$ \\
\hline CWatM & $\mathrm{GHM}^{\mathrm{b}}$ & $\begin{array}{l}\text { Penman-Monteith } \\
\text { formulation }\end{array}$ & $\begin{array}{l}\text { Degree-day } \\
\text { method }\end{array}$ & $\begin{array}{l}\text { Explicit (single } \\
\text { reservoir) }\end{array}$ & $\begin{array}{l}\text { Saturation excess, } \\
\text { baseflow }\end{array}$ & $\begin{array}{l}\text { Kinematic water } \\
\text { formulation }\end{array}$ & Yes & $\begin{array}{l}\text { Irrigation, } \\
\text { domestic, } \\
\text { industry, } \\
\text { livestock }\end{array}$ & Ref. $^{4}$ \\
\hline H08 & GHM & Bulk formulation & $\begin{array}{l}\text { Energy } \\
\text { balance } \\
\text { method }\end{array}$ & $\begin{array}{l}\text { Explicit } \\
\text { (renewable and } \\
\text { non-renewable } \\
\text { reservoirs) }\end{array}$ & $\begin{array}{l}\text { Saturation excess, } \\
\text { baseflow }\end{array}$ & $\begin{array}{l}\text { Linear reservoir } \\
\text { model }\end{array}$ & Yes & irrigation & Refs..$^{5-7}$ \\
\hline LPJmL & $\mathrm{DGVM}^{\mathrm{c}}$ & $\begin{array}{l}\text { Priestley-Taylor } \\
\text { formulation modified } \\
\text { for transpiration }\end{array}$ & $\begin{array}{l}\text { Degree-day } \\
\text { method with } \\
\text { precipitation } \\
\text { factor }\end{array}$ & $\begin{array}{l}\text { Groundwater } \\
\text { recharge and } \\
\text { runoff based on } \\
\text { seepage from } \\
\text { soil column } \\
\end{array}$ & Saturation excess & $\begin{array}{l}\text { Continuity } \\
\text { equation derived } \\
\text { from linear } \\
\text { reservoir model }\end{array}$ & Yes & Irrigation & Refs. ${ }^{8,9}$ \\
\hline MPI-HM & GHM & $\begin{array}{l}\text { Penman-Monteith } \\
\text { formulation }\end{array}$ & $\begin{array}{l}\text { Degree-day } \\
\text { method }\end{array}$ & Implicit & $\begin{array}{l}\text { Saturation excess; } \\
\text { Beta function }\end{array}$ & $\begin{array}{l}\text { Linear reservoir } \\
\text { cascade }\end{array}$ & No & Irrigation & Ref..$^{10}$ \\
\hline $\begin{array}{l}\text { PCR- } \\
\text { GLOBWB }\end{array}$ & GHM & Hamon formulation & $\begin{array}{l}\text { Degree-day } \\
\text { method }\end{array}$ & $\begin{array}{l}\text { Explicit (single } \\
\text { reservoir) }\end{array}$ & $\begin{array}{l}\text { Saturation excess; } \\
\text { groundwater } \\
\text { discharge }\end{array}$ & $\begin{array}{l}\text { Travel time routing } \\
\text { (characteristic } \\
\text { distance) linked } \\
\text { with dynamic } \\
\text { reservoir operation }\end{array}$ & Yes & $\begin{array}{l}\text { Irrigation, } \\
\text { domestic, } \\
\text { industry, } \\
\text { livestock }\end{array}$ & Ref. $^{11}$ \\
\hline WaterGAP2 & GHM & $\begin{array}{l}\text { Priestley-Taylor with } \\
\text { varying alpha-values } \\
\text { for arid and humid } \\
\text { areas }\end{array}$ & $\begin{array}{l}\text { Degree-day } \\
\text { method }\end{array}$ & $\begin{array}{l}\text { Explicit (single } \\
\text { reservoir) }\end{array}$ & $\begin{array}{l}\text { Saturation excess, } \\
\text { Beta function }\end{array}$ & $\begin{array}{l}\text { Linear reservoir } \\
\text { cascade }\end{array}$ & Yes & $\begin{array}{l}\text { Irrigation, } \\
\text { domestic, } \\
\text { electricity, } \\
\text { manufacturing, } \\
\text { livestock }\end{array}$ & Ref. $^{12}$ \\
\hline
\end{tabular}

${ }^{\mathrm{a}}$ Land Surface Model; ${ }^{\mathrm{b}}$ Global Hydrological Model; ${ }^{\mathrm{c}}$ Dynamic Global Vegetation Model. 


\section{Changes in Drought Frequency}

Supplementary Table 4 | Continent-based normalized frequency of TWS drought and its change from the historical baseline period (HIST) to the end of the twenty-first century

(RCP6.0). Shown are the numbers associated with the histograms presented in Figures $\mathbf{4 c - h}$ in the main text. "Bin width" represents the width of each bin on the x-axis of the histograms. The last two columns present the cumulative area (i.e., cumulative normalized frequency for HIST and RCP6.0 simulations). The cells color-coded green show the cumulative normalized frequency for TWS-DSI categories considered as droughts (Supplementary Table 1). For example, the cumulative frequency for Africa changed from 21.44 to $38 \%$, suggesting an increase of $\sim 17 \%$; the same for South America is $\sim 34 \%$ and those for the other continents (except Asia) are in between.

\begin{tabular}{|c|c|c|c|c|c|c|c|c|c|c|c|c|c|}
\hline 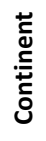 & TWS-DSI & $\begin{array}{l}\text { Bin } \\
\text { Width }\end{array}$ & $\begin{array}{l}\text { Norm. } \\
\text { Freq. } \\
\text { (HIST) }\end{array}$ & $\begin{array}{l}\text { Norm. } \\
\text { Freq. } \\
\text { (RCP6.0) }\end{array}$ & $\begin{array}{l}\text { Cum. } \\
\text { Area } \\
\text { (HIST, } \\
\% \text { ) }\end{array}$ & $\begin{array}{l}\text { Cum. } \\
\text { Area } \\
\text { (RCP6.0, } \\
\text { \%) }\end{array}$ & 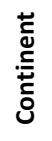 & TWS-DSI & $\begin{array}{l}\text { Bin } \\
\text { Width }\end{array}$ & $\begin{array}{l}\text { Norm. } \\
\text { Freq. } \\
\text { (HIST) }\end{array}$ & $\begin{array}{l}\text { Norm. } \\
\text { Freq. } \\
\text { (RCP6.0) }\end{array}$ & $\begin{array}{l}\text { Cum. } \\
\text { Area } \\
\text { (HIST, } \\
\% \text { ) }\end{array}$ & $\begin{array}{l}\text { Cum. } \\
\text { Area } \\
\text { (RCP6.0, } \\
\text { \%) }\end{array}$ \\
\hline \multirow{11}{*}{ 畩 } & $-3.0 \sim-2.0$ & 1 & 0.0061 & 0.0495 & 0.61 & 4.95 & \multirow{11}{*}{ 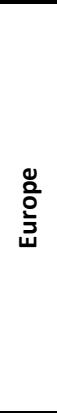 } & $-3.0 \sim-2.0$ & 1 & 0.0131 & 0.0491 & 1.31 & 4.91 \\
\hline & $-2.0 \sim-1.6$ & 0.4 & 0.0405 & 0.1702 & 2.23 & 11.76 & & $-2.0 \sim-1.6$ & 0.4 & 0.0359 & 0.1477 & 2.75 & 10.82 \\
\hline & $-1.6 \sim-1.3$ & 0.3 & 0.0868 & 0.2531 & 4.83 & 19.35 & & $-1.6 \sim-1.3$ & 0.3 & 0.0568 & 0.1876 & 4.45 & 16.45 \\
\hline & $-1.3 \sim-0.8$ & 0.5 & 0.1508 & 0.2443 & 12.37 & 31.57 & & $-1.3 \sim-0.8$ & 0.5 & 0.1125 & 0.2295 & 10.08 & 27.92 \\
\hline & $-0.8 \sim-0.5$ & 0.3 & 0.3023 & 0.2145 & 21.44 & 38.00 & & $-0.8 \sim-0.5$ & 0.3 & 0.1823 & 0.2482 & 15.54 & 35.37 \\
\hline & $-0.5 \sim+0.5$ & 1 & 0.4367 & 0.2504 & 65.11 & 63.04 & & $-0.5 \sim+0.5$ & 1 & 0.3571 & 0.3144 & 51.25 & 66.81 \\
\hline & $+0.5 \sim+0.8$ & 0.3 & 0.3725 & 0.3108 & 76.29 & 72.37 & & $+0.5 \sim+0.8$ & 0.3 & 0.4544 & 0.3185 & 64.89 & 76.36 \\
\hline & $+0.8 \sim+1.3$ & 0.5 & 0.2758 & 0.2549 & 90.08 & 85.11 & & $+0.8 \sim+1.3$ & 0.5 & 0.3758 & 0.2499 & 83.68 & 88.86 \\
\hline & $+1.3 \sim+1.6$ & 0.3 & 0.1518 & 0.1886 & 94.63 & 90.77 & & $+1.3 \sim+1.6$ & 0.3 & 0.2765 & 0.1742 & 91.97 & 94.08 \\
\hline & $+1.6 \sim+2.0$ & 0.4 & 0.0762 & 0.1202 & 97.68 & 95.58 & & $+1.6 \sim+2.0$ & 0.4 & 0.1354 & 0.1017 & 97.39 & 98.15 \\
\hline & $+2.0 \sim+3.0$ & 1 & 0.0232 & 0.0442 & 100.00 & 100.00 & & $+2.0 \sim+3.0$ & 1 & 0.0261 & 0.0185 & 100.00 & 100.00 \\
\hline \multirow{11}{*}{$\frac{\pi}{4}$} & $-3.0 \sim-2.0$ & 1 & 0.0085 & 0.0377 & 0.85 & 3.77 & \multirow{11}{*}{ 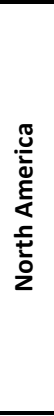 } & $-3.0 \sim-2.0$ & 1 & 0.0057 & 0.0905 & 0.57 & 9.05 \\
\hline & $-2.0 \sim-1.6$ & 0.4 & 0.0337 & 0.1637 & 2.20 & 10.32 & & $-2.0 \sim-1.6$ & 0.4 & 0.0268 & 0.3274 & 1.64 & 22.15 \\
\hline & $-1.6 \sim-1.3$ & 0.3 & 0.0673 & 0.1739 & 4.22 & 15.54 & & $-1.6 \sim-1.3$ & 0.3 & 0.0734 & 0.3388 & 3.84 & 32.31 \\
\hline & $-1.3 \sim-0.8$ & 0.5 & 0.1658 & 0.1705 & 12.51 & 24.06 & & $-1.3 \sim-0.8$ & 0.5 & 0.1241 & 0.2336 & 10.05 & 43.99 \\
\hline & $-0.8 \sim-0.5$ & 0.3 & 0.2602 & 0.1646 & 20.31 & 29.00 & & $-0.8 \sim-0.5$ & 0.3 & 0.2216 & 0.1548 & 16.70 & 48.63 \\
\hline & $-0.5 \sim+0.5$ & 1 & 0.4689 & 0.1904 & 67.20 & 48.04 & & $-0.5 \sim+0.5$ & 1 & 0.4329 & 0.1909 & 59.99 & 67.72 \\
\hline & $+0.5 \sim+0.8$ & 0.3 & 0.4792 & 0.3096 & 81.58 & 57.33 & & $+0.5 \sim+0.8$ & 0.3 & 0.5359 & 0.3457 & 76.06 & 78.10 \\
\hline & $+0.8 \sim+1.3$ & 0.5 & 0.2657 & 0.4136 & 94.86 & 78.01 & & $+0.8 \sim+1.3$ & 0.5 & 0.3351 & 0.2984 & 92.82 & 93.02 \\
\hline & $+1.3 \sim+1.6$ & 0.3 & 0.0923 & 0.3588 & 97.63 & 88.77 & & $+1.3 \sim+1.6$ & 0.3 & 0.1317 & 0.1465 & 96.77 & 97.41 \\
\hline & $+1.6 \sim+2.0$ & 0.4 & 0.0378 & 0.1941 & 99.15 & 96.53 & & $+1.6 \sim+2.0$ & 0.4 & 0.0504 & 0.0529 & 98.79 & 99.53 \\
\hline & $+2.0 \sim+3.0$ & 1 & 0.0084 & 0.0346 & 99.99 & 99.99 & & $+2.0 \sim+3.0$ & 1 & 0.0121 & 0.0047 & 100.00 & 100.00 \\
\hline \multirow{11}{*}{ 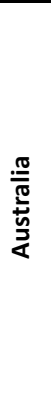 } & $-3.0 \sim-2.0$ & 1 & 0.0025 & 0.0267 & 0.25 & 2.67 & \multirow{11}{*}{ 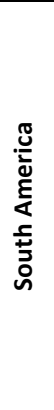 } & $-3.0 \sim-2.0$ & 1 & 0.0063 & 0.0916 & 0.63 & 9.16 \\
\hline & $-2.0 \sim-1.6$ & 0.4 & 0.0207 & 0.1802 & 1.08 & 9.88 & & $-2.0 \sim-1.6$ & 0.4 & 0.0346 & 0.2642 & 2.01 & 19.73 \\
\hline & $-1.6 \sim-1.3$ & 0.3 & 0.0537 & 0.3203 & 2.69 & 19.49 & & $-1.6 \sim-1.3$ & 0.3 & 0.0746 & 0.29 & 4.25 & 28.43 \\
\hline & $-1.3 \sim-0.8$ & 0.5 & 0.1574 & 0.3854 & 10.56 & 38.76 & & $-1.3 \sim-0.8$ & 0.5 & 0.1484 & 0.3117 & 11.67 & 44.01 \\
\hline & $-0.8 \sim-0.5$ & 0.3 & 0.303 & 0.3588 & 19.65 & 49.52 & & $-0.8 \sim-0.5$ & 0.3 & 0.2638 & 0.3066 & 19.59 & 53.21 \\
\hline & $-0.5 \sim+0.5$ & 1 & 0.4026 & 0.2796 & 59.91 & 77.48 & & $-0.5 \sim+0.5$ & 1 & 0.4001 & 0.2534 & 59.60 & 78.55 \\
\hline & $+0.5 \sim+0.8$ & 0.3 & 0.3615 & 0.1973 & 70.75 & 83.40 & & $+0.5 \sim+0.8$ & 0.3 & 0.4343 & 0.1955 & 72.63 & 84.42 \\
\hline & $+0.8 \sim+1.3$ & 0.5 & 0.2669 & 0.1565 & 84.10 & 91.23 & & $+0.8 \sim+1.3$ & 0.5 & 0.3132 & 0.1379 & 88.29 & 91.31 \\
\hline & $+1.3 \sim+1.6$ & 0.3 & 0.1756 & 0.1151 & 89.37 & 94.68 & & $+1.3 \sim+1.6$ & 0.3 & 0.1898 & 0.1062 & 93.98 & 94.50 \\
\hline & $+1.6 \sim+2.0$ & 0.4 & 0.1438 & 0.068 & 95.12 & 97.40 & & $+1.6 \sim+2.0$ & 0.4 & 0.1045 & 0.0771 & 98.16 & 97.58 \\
\hline & $+2.0 \sim+3.0$ & 1 & 0.0488 & 0.026 & 100.00 & 100.00 & & $+2.0 \sim+3.0$ & 1 & 0.0185 & 0.0242 & 100.01 & 100.00 \\
\hline
\end{tabular}




\section{Comparison of simulated TWS seasonality with GRACE data}
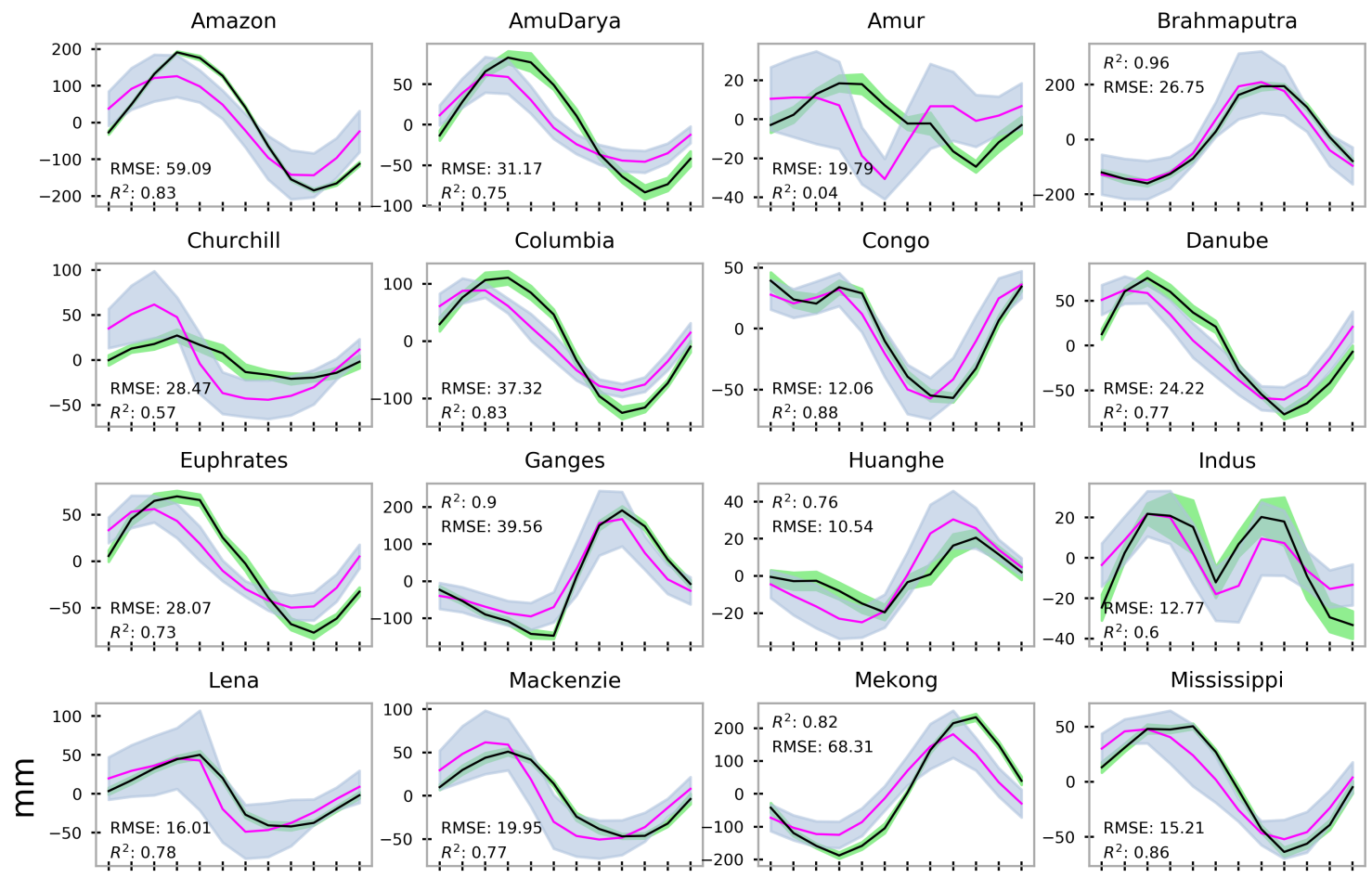

Mackenzie

Mekong
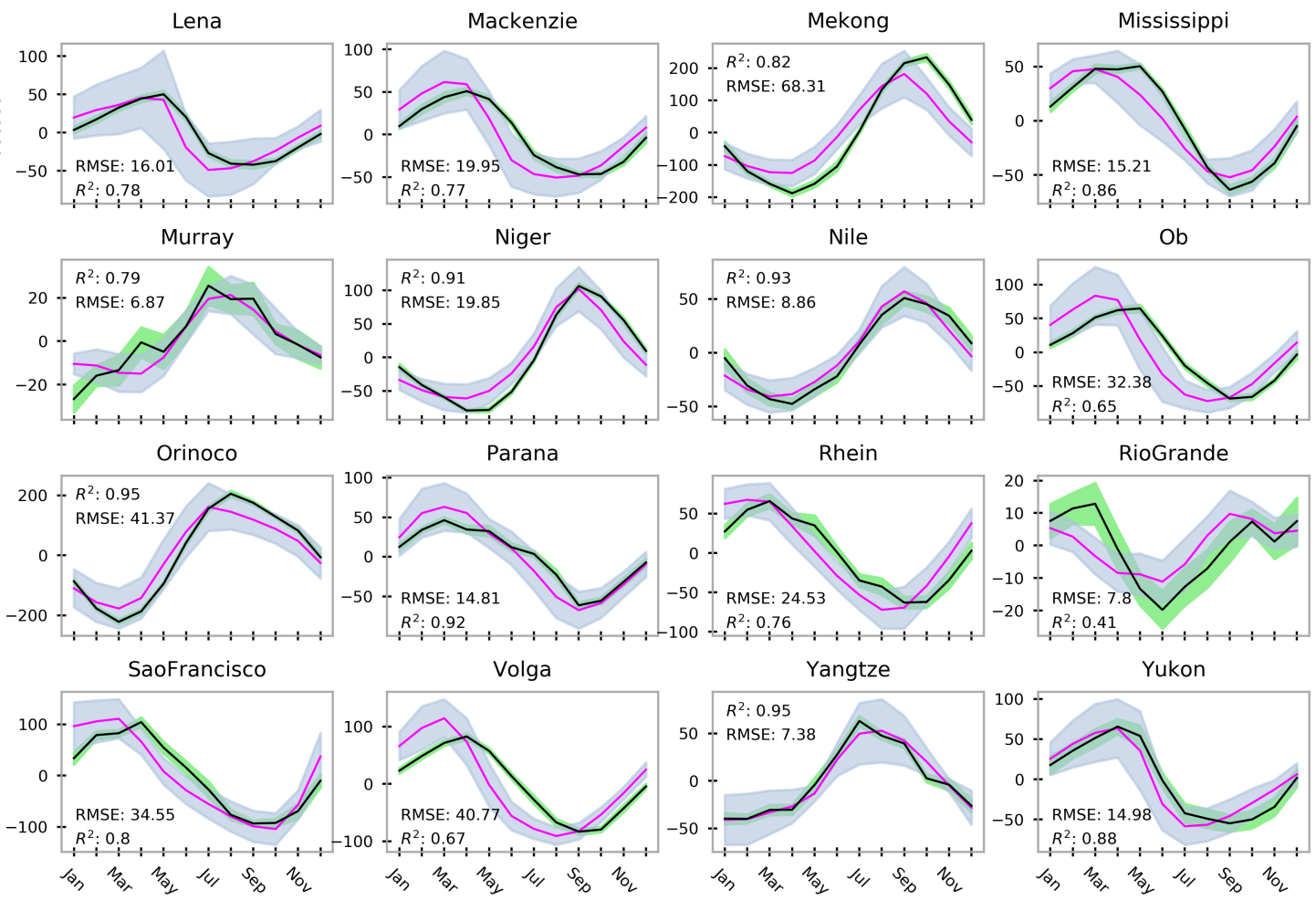

__ Unweighted Mean

$\pm 1 S D$

GRACE

GRACE Range

Supplementary Fig. 1 | Monthly seasonal cycle (2002-2016) of TWS for the major global river basins. GRACE data are the mean of two mascon products (CSR and JPL; see Methods for more details). Gray shading indicates the spread among 27 ensemble members expressed as one standard deviation (SD) from the mean. The method used to calculate the anomalies is similar to that used in Extended Data Figure 5. Note that we use the simple ensemble average, not the weighted mean, for these comparisons to provide an unbiased evaluation of the models and to ensure that the model-GRACE agreement is not a result of the weighting that is based on the GRACE data. Green shading indicates the range between the two GRACE products. 


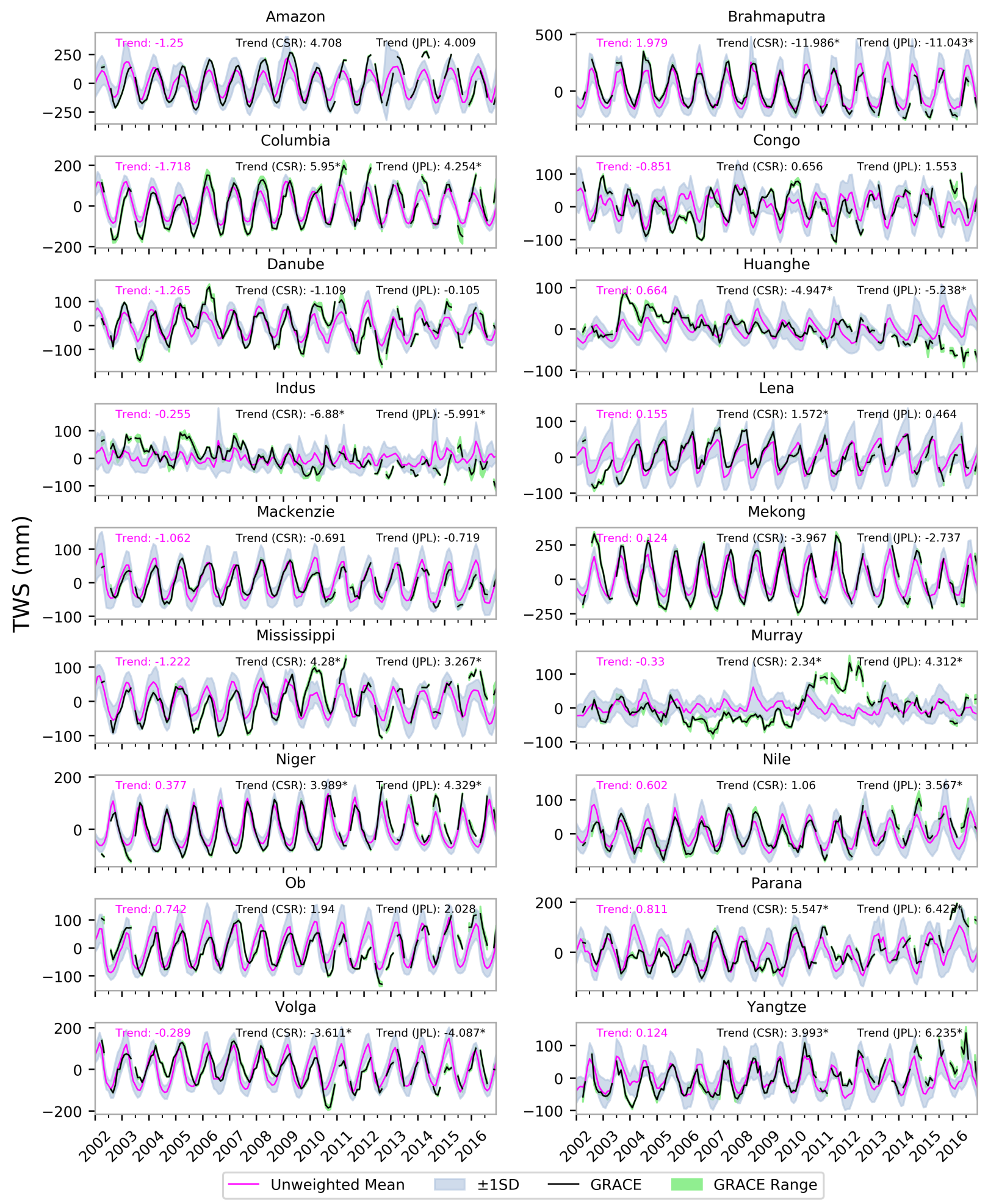

Supplementary Fig. 2 | Comparison of simulated TWS with GRACE data. The same results as in Supplementary Figure 1, but shown as complete time series (2002-2016) for a subset of basins located in different geographic and climatic regions. 


\section{The Selected IPCC SREX Regions}

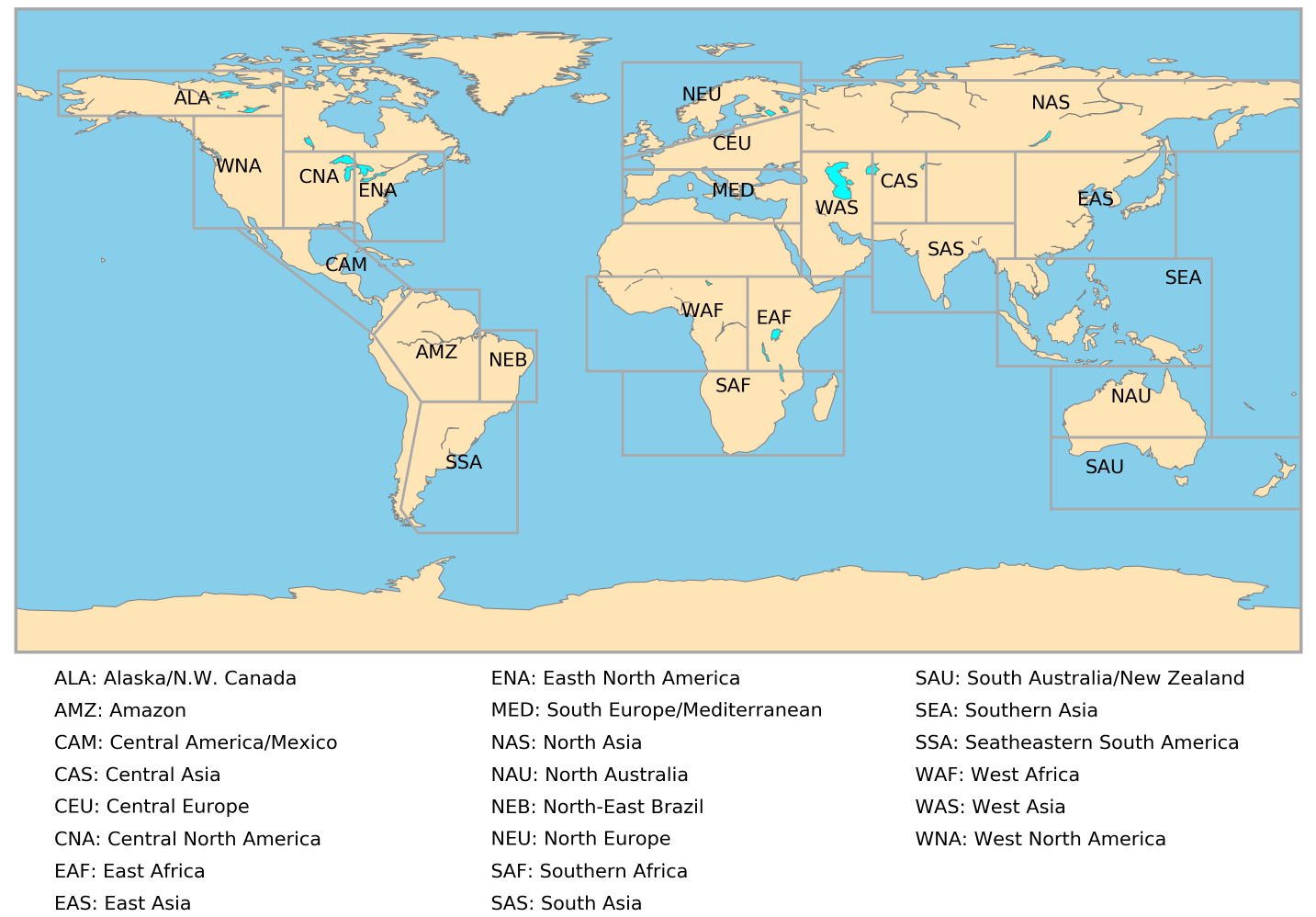

Supplementary Fig. 3 | Geographic location and description of the selected IPCC SREX regions. These are the sub-continental regions defined by the Intergovernmental Panel on Climate Change (IPCC) Special Report on Extremes (SREX). 


\section{Changes in drought conditions under climate change}

(a)
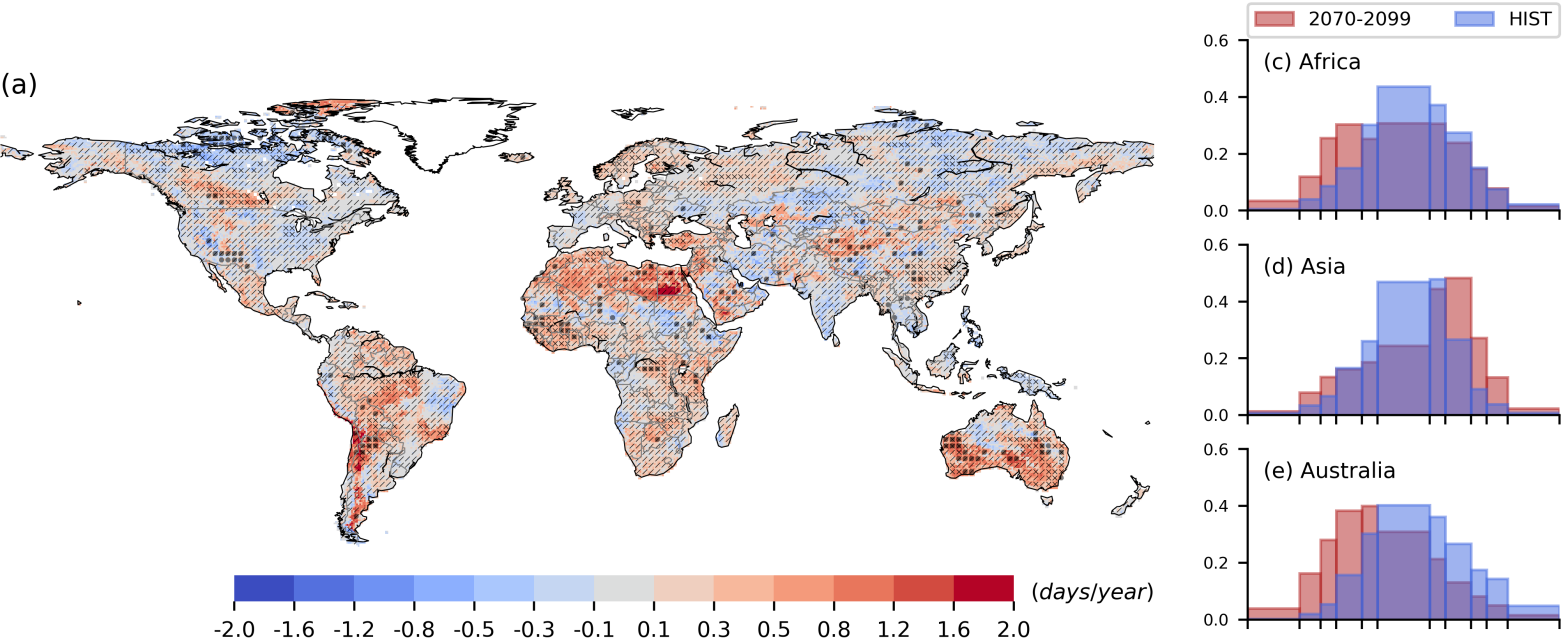

(b)
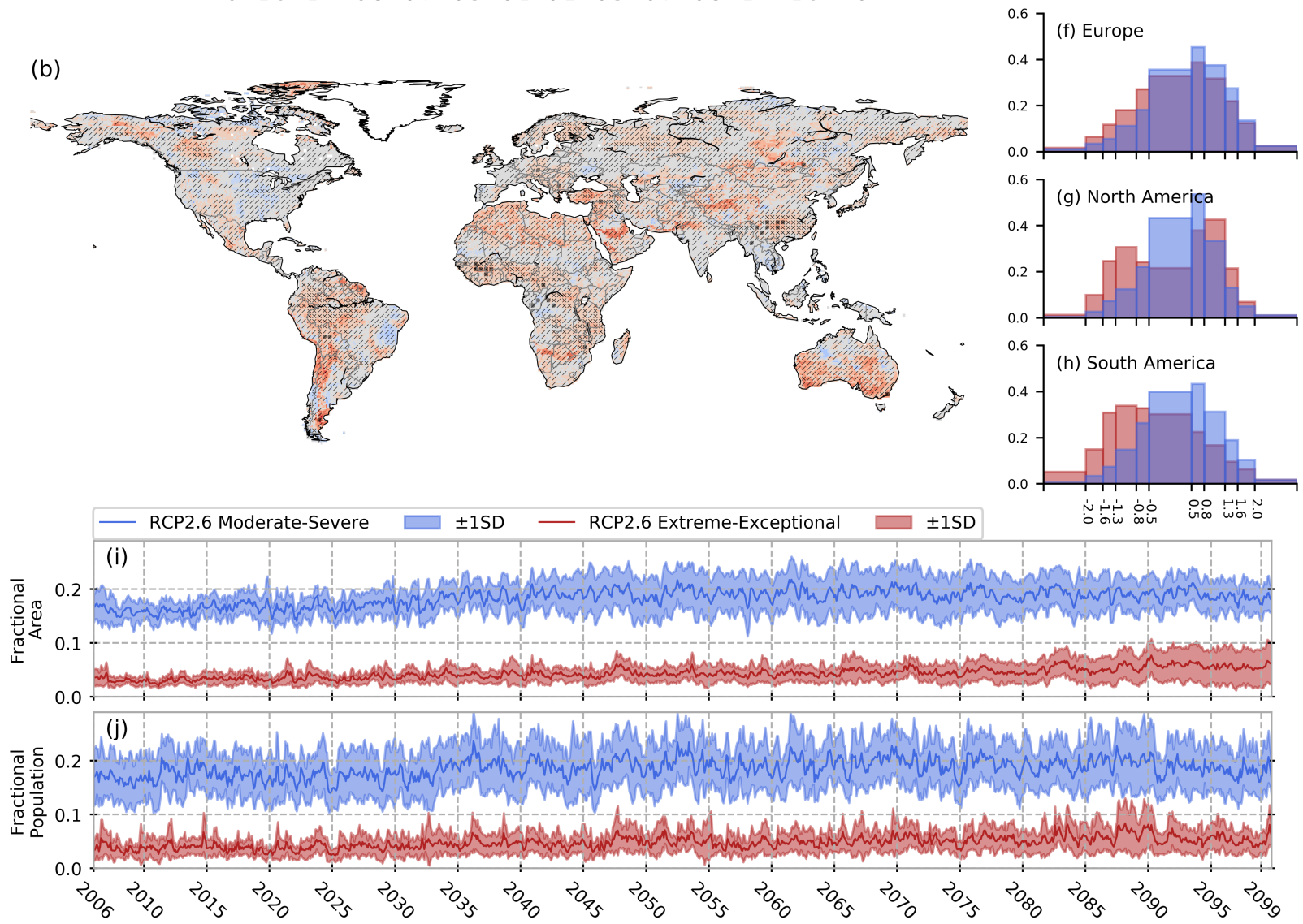

Supplementary Fig. 4 | Projected changes in occurrence and time evolution of droughts.

Same as in Figure 4 in the main text but for RCP2.6. 


\section{Changes in TWS drought PDFs for SREX regions}



Supplementary Fig. 5 | Probability density function of monthly TWS-DSI for IPCC SREX regions. Same as in Figure 5 in the main text but for the mid- $21^{\text {st }}$ century. 


\section{References}

1 Zhao, M., Velicogna, I. \& Kimball, J. S. Satellite observations of regional drought severity in the continental United States using GRACE-based terrestrial water storage changes. J. Climate 30, 6297-6308 (2017).

2 Lawrence, D. M. et al. Parameterization improvements and functional and structural advances in Version 4 of the Community Land Model. J. Adv. Model. Earth Syst. 3, M03001, doi:10.1029/2011MS00045 (2011).

3 Oleson, K. W. Technical Description of version 4.5 of the Community Land Model (CLM). 422 (National Center for Atmospheric Research, Boulder, CO, 2013).

4 Burek, P. et al. Development of the Community Water Model (CWatM v1.04) A high-resolution hydrological model for global and regional assessment of integrated water resources management. Geosci. Model Dev. Discuss. 2019, 1-49, doi:10.5194/gmd-2019-214 (2019).

$5 \quad$ Hanasaki, N. et al. An integrated model for the assessment of global water resources - Part 1: Model description and input meteorological forcing. Hydrol. Earth Syst. Sci. 12, 1007-1025, doi:10.5194/hess-12-1007-2008 (2008).

$6 \quad$ Hanasaki, N. et al. An integrated model for the assessment of global water resources - Part 2: Applications and assessments. Hydrol. Earth Syst. Sci. 12, 1027-1037, doi:10.5194/hess-12-10272008 (2008).

7 Hanasaki, N., Yoshikawa, S., Pokhrel, Y. \& Kanae, S. A global hydrological simulation to specify the sources of water used by humans. Hydrol. Earth Syst. Sci. 22, 789-817, doi:10.5194/hess-22-789-2018 (2018).

8 Bondeau, A. et al. Modelling the role of agriculture for the 20th century global terrestrial carbon balance. Global Change Biology 13, 679-706, doi:10.1111/j.1365-2486.2006.01305.x (2007).

9 Rost, S. et al. Agricultural green and blue water consumption and its influence on the global water system. Water Resources Research 44, W09405, doi:10.1029/2007WR006331 (2008).

10 Stacke, T. \& Hagemann, S. Development and evaluation of a global dynamical wetlands extent scheme. Hydrol. Earth Syst. Sci. 16, 2915-2933, doi:10.5194/hess-16-2915-2012 (2012).

11 Wada, Y., Wisser, D. \& Bierkens, M. F. P. Global modeling of withdrawal, allocation and consumptive use of surface water and groundwater resources. Earth Syst. Dynam. 5, 15-40, doi:10.5194/esd-5-15-2014 (2014).

12 Mueller Schmied, H. et al. Variations of global and continental water balance components as impacted by climate forcing uncertainty and human water use. Hydrology and Earth System Sciences 20, 2877-2898 (2016). 